\title{
Preliminary Design of Integrated Partial Turboelectric Aircraft Propulsion Systems
}

\section{Original article}

Article history:

Submission date: 31 August 2021

Acceptance date: 17 January 2022

Publication date: 25 February 2022

Check for updates

*Correspondence:

MP: m.pohl@ist.rwth-aachen.de

\section{Peer review:}

Single blind

\section{Copyright:}

(C) 2022 Pohl et al. @ This is an open access article distributed under the Creative Commons Attribution Non Commercial No Derivatives License (CC BY-NC-ND 4.0). Unrestricted use, distribution, and reproduction of the original work are permitted for noncommercial purposes only, provided it is properly cited and its authors credited. No derivative of this work may be distributed.

\section{Keywords:}

power electronics; electric component modeling; electric powertrain; wingtip propeller; electric machine; partial turboelectric

\section{Citation:}

Pohl M., Köhler J., Kellermann H., Lüdemann M., Weintraub D., Jeschke P., and Hornung M. (2022). Preliminary Design of Integrated Partial Turboelectric Aircraft Propulsion Systems. Journal of the Global Power and Propulsion Society. 6: 1-23. https://doi.org/10.33737/jgpps/145907

\author{
Markus Pohl ${ }^{1, *}$, Jo Köhler ${ }^{1}$, Hagen Kellermann ${ }^{2}$, Michael Lüdemann ${ }^{2}$, \\ Daniel Weintraub ${ }^{3}$, Peter Jeschke $^{1}$, Mirko Hornung $^{2}$ \\ ${ }^{1}$ Institute of Jet Propulsion and Turbomachinery, RWTH Aachen University, Aachen, Germany \\ ${ }^{2}$ Bauhaus Luftfahrt e. V., Taufkirchen, Germany \\ ${ }^{3}$ GasTurb GmbH, Aachen, Germany
}

\begin{abstract}
This paper presents a novel tool for the modeling of partial turboelectric propulsion systems together with a corresponding case study for a commercial single-aisle aircraft. In order to reduce the environmental impact of air traffic, radically new aircraft and propulsion concepts with a high market penetration are needed. Partial turboelectric propulsion systems seem to offer a promising option to achieve this. For the development of these propulsion systems, a preliminary design tool with a homogeneous and sufficiently high fidelity, both for turbomachinery and electric components, is needed. To address this, the authors of this publication have developed a tool based on the GasTurb software. The models developed, in particular for the electric components which together form the electric powertrain, are described here. In the case study, which demonstrates the coupling of the developed tool with an aircraft design environment, a conventional turboprop baseline aircraft is compared to a derived aircraft which features a partial turboelectric propulsion system with wingtip propellers. The latter are intended to reduce the induced drag, enabling a reduction of the aircraft's total shaft power demand compared to the conventional baseline aircraft. The comparison between the partial turboelectric aircraft and the baseline aircraft indicates that fuel reduction increases with power split. However, primarily increasing electric powertrain masses and a stagnating drag reduction result in lower additional fuel reductions for higher power splits. Despite these conclusions, the predicted induced drag reductions need further refinement as they were found to be optimistic. In summary, this publication presents a methodology and a set of physics-based component models for the preliminary design of partial turboelectric propulsion systems, so that the electric components can be investigated and optimized at the same high level of detail as the gas turbine.
\end{abstract}

\section{Introduction}

In general, the developmental process for a commercial aircraft, from the initial design concept to its certification and entry into service takes several years. The same is true for its accompanying propulsion system. Furthermore, they tend to remain in service for a few decades after coming onto the market. Consequently, an aircraft type certified in 2021 might still be operational in 2050. In order to achieve the ambitious environmental goals of the Flightpath 2050 vision (Advisory Council for Aeronautics Research in Europe, 2011), radical new solutions for aircraft propulsion systems are needed in less than an aircraft's life cycle. For this reason, the development of these new aircraft and propulsion systems have to begin immediately. 
Many propulsion systems which differ from conventional combustion-based engines-including internal combustion engines and gas turbines-have been already investigated. The first small all-electric short-range aircraft, with restricted mission capabilities, received its type certificate from the European Union Aviation Safety Agency in 2020 (Pipistrel Group, 2020). Despite some new commuter aircraft concepts (Eviation, 2020; Zunum Aero, 2020) no aircraft in this segment with a turbo-, all-electric or hybrid propulsion system has entered the market yet. In this respect, it will be a long time before electrified single-aisle aircraft could enter into service.

When considering different propulsion systems, aircraft designers have to conduct a number of studies in order to identify the optimum solution for the given mission. For commercial aircraft, only gas turbine engines have been relevant over the last decades. In this domain, besides GasTurb (GasTurb GmbH, 2020), other preliminary design tools like GSP (NLR - Royal Netherlands Aerospace Centre, 2020), NPSS (Southwest Research Institute, 2020), and PROOSIS (EA Internacional, 2020) are also being offered commercially. Several modules for the modeling of electric components were developed in NPSS (Perullo et al., 2014) and PROOSIS (Athanasakos et al., 2020). The same applies to a number of multi domain simulation programs (Sielemann et al., 2020; Kang et al., 2021). Commonly, it is up to the user to integrate different modules into the propulsion system in a sensible way. Based on GasTurb, the authors of this publication have developed modules for the simulation of electric components with the same fidelity as the conventional engine components. These modules can be used for modeling all relevant types of turboelectric and hybrid aircraft propulsion systems. The GasTurb software is unique in that it comes with preconfigured propulsion architectures, to support performance and pre-design studies. Complete electric powertrains are provided to the user, which are readily usable and can be combined with almost any gas turbine architecture. One of these combinations is the partial turboelectric propulsion system architecture, which therefore could be investigated in a level of detail that has not been described before.

\section{Aircraft and propulsion system concept}

According to the Committee on Propulsion and Energy Systems to Reduce Commercial Aviation Carbon Emissions (2016), more than one third of the $\mathrm{CO}_{2}$ emissions from global commercial aviation is generated by single-aisle aircraft. Because of their significance, prior to the work for this paper, Bauhaus Luftfahrt investigated hybrid propulsion systems for these aircraft. For example, Vratny and Hornung (2018) investigated a 180-passenger aircraft with a range of 1,300 NM. They compared the energy consumption of a conventional aircraft, using two geared turbofans, to a parallel hybrid aircraft with two additional electrically driven fans. The electric fans were wing-mounted and for the battery a gravimetric energy density of $1,000 \mathrm{Wh} / \mathrm{kg}$ was assumed. In comparison to the geared turbofans, the hybrid propulsion system was not able to reduce the energy required for the mission. In order to lower the energy demand, instead of simply replacing conventional engines, the propulsion system also needs to be closely integrated. In this context, integration is intended to bring about a beneficial interaction between the propulsion system and the other aircraft parts, especially with regard to aerodynamics. During aircraft design, this requires close communication between aircraft and propulsion system designers. Following the study carried out by Vratny and Hornung (2018), this paper focuses on single-aisle aircraft. Initially, the same top-level aircraft requirements (TLARs) were also used. However, for this paper an integrated propulsion system architecture and a lower design cruise Mach number were selected. This selection will be explained in the following paragraphs.

Geared turbofan engines are currently the most advanced propulsion technology for commercial single-aisle aircraft. However, the use of turboprop engines opens up further potential to reduce fuel consumption when a technologically appropriate design flight Mach number below 0.7 is accepted. Moreover, this propulsion technology favors the use of wingtip propellers, as the operational regime of the constant speed propellers facilitates the easy transfer of large amounts of power. Research activities by Strack et al. (2017) from the German Aerospace Center have shown that a regional aircraft with a turboprop engine-based hybrid electric propulsion system can bring about a slight reduction in the mission fuel and energy demand while the aircraft's maximum takeoff mass (MTOM) remains almost constant. The combined parallel and series hybrid propulsion system for the concept aircraft includes wingtip propellers. Similar results have been found by Antcliff and Capristan (2017) and Blaesser and Frederick (2020) from NASA, who have investigated a regional aircraft with a parallel hybrid propulsion system including wingtip propellers. Both studies of German Aerospace Center and NASA assume that the battery has an energy density of $500 \mathrm{Wh} / \mathrm{kg}$. However, for the propulsion of the aircraft class studied in this paper, significantly higher power is required than for regional aircraft. The anticipated battery mass would drastically increase the MTOM. For this reason, we concluded that, for a medium-term application, partial turboelectric propulsion using wingtip propellers is a more promising option. As such, a partial turboelectric propulsion system consisting 


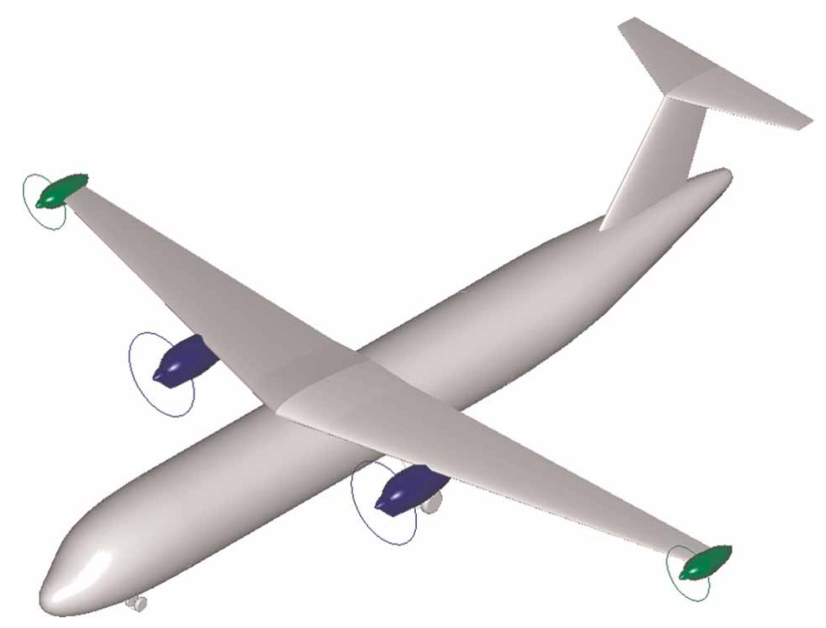

Figure 1. The partial turboelectric aircraft with advanced turboprop engines (blue), featuring mechanically driven main propellers and generators, and the electrically driven wingtip propellers (green).

of advanced turboprop engines and electrically driven wingtip propellers was evaluated. Although a higher design range would be more favorable for this propulsion system architecture, it was kept constant for two reasons. The first one is to pursue the research question of Vratny and Hornung (2018) and the second one is to assess a lowerboundary design range. For the evaluation in the case study, a conventional turboprop baseline aircraft is compared to a derivative with the partial turboelectric propulsion system, see Figure 1. Both aircraft have to fulfil the same TLARs, which can be found in Table 1 . Based on the goals mentioned at the beginning of this paper, the entry into service is projected for 2035.

A diagram of the partial turboelectric propulsion system is shown in Figure 2. The upper part of the figure shows the rather conventional advanced turboprop engine. The lower part of the figure shows the electric part of the propulsion system, hereafter referred to as electric powertrain, which is used to drive the wingtip propeller.

Table 1. Top-level aircraft requirements.

\begin{tabular}{|l|l|}
\hline Passengers & $180^{\mathrm{a}}$ \\
\hline Range & $1,300 \mathrm{NM}^{\mathrm{b}}$ \\
\hline Time to climb & $<25 \mathrm{~min}^{\mathrm{c}}$ \\
\hline Initial cruise altitude & Optimization parameter \\
\hline Takeoff field length & $6,000 \mathrm{ft}^{\mathrm{d}}$ \\
\hline Design cruise Mach number & 0.68 \\
\hline Maximum cruise altitude & $41,000 \mathrm{ft}$ \\
\hline Approach speed & $130 \mathrm{KCAS}$ \\
\hline Landing field length & $5,250 \mathrm{ft}^{\mathrm{e}}$ \\
\hline One-engine inoperative alt. & $17,000 \mathrm{ft}$ \\
\hline Year of entry into service & 2,035 \\
\hline
\end{tabular}

${ }^{a} 222$ passengers in high-density layout ${ }^{b}$ with 180 passengers ${ }^{c}$ obstacle height to initial cruise altitude, international standard atmosphere (ISA) $+10 \mathrm{~K}$

${ }^{d}$ maximum takeoff mass, ISA sea-level ${ }^{\mathrm{e}}$ maximum landing mass, ISA sea-level. 


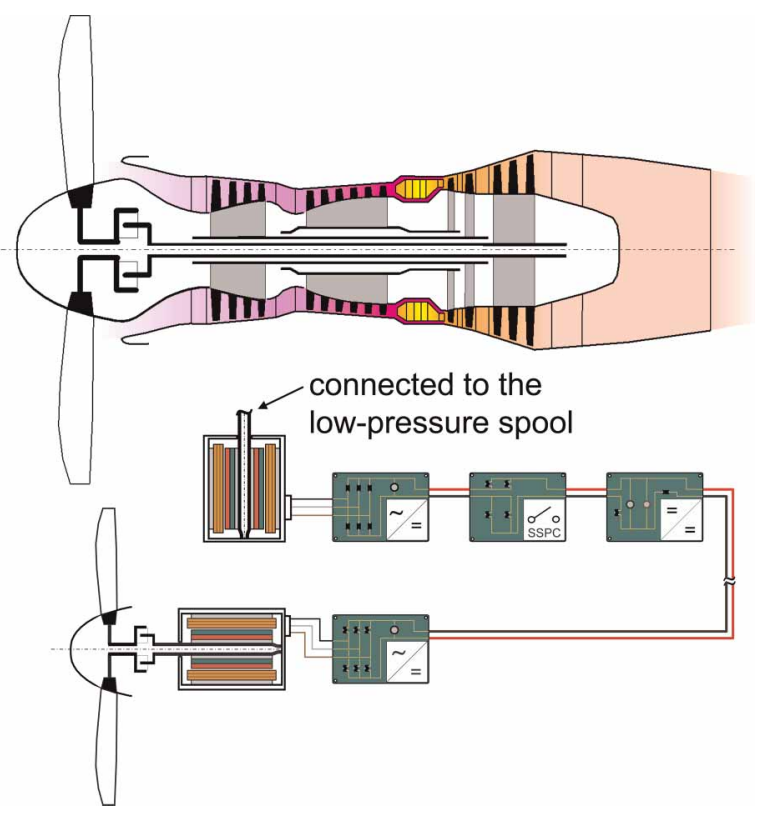

Figure 2. Advanced turboprop engine and electric powertrain of the partial turboelectric propulsion system.

The generator of the electric powertrain is directly connected to the free power turbine of the engine, which also drives the main propeller via a gearbox. A more detailed description of the electric powertrain is presented in the modeling section below. Due to the all-electric subsystems of both the baseline and the partial turboelectric aircraft, the baseline and the advanced turboprop engines are presumed to feature bleedless designs. Instead of bleed air demand, the aircraft have an increased electric power demand for their subsystems. This additional demand is the same for both aircraft and is also covered by the turboprop engines. In this way, the aircraft and propulsion concept is set. In the following section, the methodology used will be explained.

\section{Methodology}

The first subsection describes the modeling of the aircraft and the modeling of the propulsion system, including its individual components. The modeling forms the foundation for understanding the preliminary partial turboelectric propulsion system design process. This process is explained in the ensuing subsection.

\section{System and component modeling}

In order to describe the dimensions, masses and characteristics of the aircraft and the propulsion system during the design process, models are needed. The scope of these models must be aligned with the tasks within the scope of the preliminary design. For the aircraft modeling only a short overview is given. The individual propulsion system components-both those of the gas turbine and those of the electrical system-are represented by analytical equations in mathematical-physical models. As for the aircraft, only a brief introduction is given for the gas turbine modeling. The focus is on the electric powertrain, for which a detailed description is provided.

\section{Aircraft modeling}

The aircraft design software Pacelab APD (PACE Aerospace Engineering \& Information Technology GmbH, 2012) was used as the central integration platform and development environment for the various disciplines which are typically involved in conceptual and preliminary aircraft design. This software is mainly based on wellknown semi-empirical methods developed by Raymer (2006) and Torenbeek (2010). It was extended with more sophisticated methods, as presented by Gologan (2010), Seitz (2012), Pornet (2018), Vratny (2019), and also with mass estimation methods from Arbeitskreis Masseanalyse des Luftfahrttechnischen Handbuchs (2008). They are applied to calculate the aircraft's aerodynamics, geometries, masses and to analyze their performances. To coincide with the entry into service in 2035, technological improvements are anticipated for the structure and aerodynamics of the aircraft, as well as in the material science domain.

The propeller sizing is closely coupled to the aircraft sizing and the mutual interference of the propellers and the wing. Therefore, the propellers were modeled in the aircraft domain. Since the partial turboelectric aircraft 
features wingtip propellers to reduce fuel consumption by lowering the aircraft's induced drag, the set of methods described had to be extended with a method which is capable of predicting this aerodynamic effect. No literature about a comparison of the predicted and actually measured induced thrust for comparable geometries and flight conditions as used in the case study was found. However, the work of Loth and Loth (1984), resulting in analytical formulae to account for the induced thrust created due to the utilization of wingtip propellers, was found superior compared to the simplified correlations presented in other publications. E.g., the correlations of Miranda and Brennan (1986) only apply to a distinct flight state, geometry, and performance setting. In contrast, the physics-based formulae from Loth and Loth (1984) are solved by providing information about the atmosphere, the aircraft's flight condition, the wing geometry, the operating conditions, and geometries of the propellers. Consequently, equations based on these formulae were integrated into Pacelab APD in line with the fidelity level of the methods already used. Nevertheless, the uncertainties in the validity of the associated predictions must be kept in mind and resolved in future work but were found acceptable as the case study presented in this paper is meant to be a software and capability demonstration.

\section{Propeller modeling}

The propeller calculations carried out follow the methodology presented in the GasTurb manual (GasTurb $\mathrm{GmbH}, 2020)$. Here, the actual propeller performance is predicted using a propeller map from Wainauski et al. (1987), which applies to prop-fans with flight Mach numbers similar to 0.68 from the TLARs. This map is scaled to match the desired propeller design at top of climb (TOC) and used for off-design calculations.

\section{Gas turbine modeling}

The gas turbine modeling is accomplished by using the GasTurb performance calculation software. This has been described in several papers by the software developer Kurzke (2007). During the design phase, the engine's dimensions and mass are determined. Equally to the propeller, the gas turbines for the paper were designed at TOC. The engine's off-design characteristics are estimated using scaled component maps. Detailed information about the general modeling can be found in the software manual (GasTurb GmbH, 2020).

As part of the turboprop engine preliminary design, the turbomachinery components are scrutinized. The compressor efficiency estimations, which are derived from empirical data, as well as the compressor design, are verified with the compressor mean line design tool included in GasTurb using empirical loss correlations. The turbine efficiencies are also derived from empirical data and the turbine stage loadings are checked with respect to their feasibility. Cooling air demand significantly influences the optimal process parameters. For that reason, this must be considered during optimization. The cooling air demands for the high and intermediate pressure turbines are deduced from Grieb (2004). The component efficiencies and the cooling air requirements were adjusted to an anticipated entry into service in 2035 .

\section{Electric powertrain}

The electric powertrain, see Figure 3, is a crucial subsystem of the partial turboelectric propulsion system and is described in more detail below. It consists of a generator, a rectifier, a direct current (DC) to DC converter, a power controller, an inverter and an electric motor, which drives the propeller. The generator is connected to the

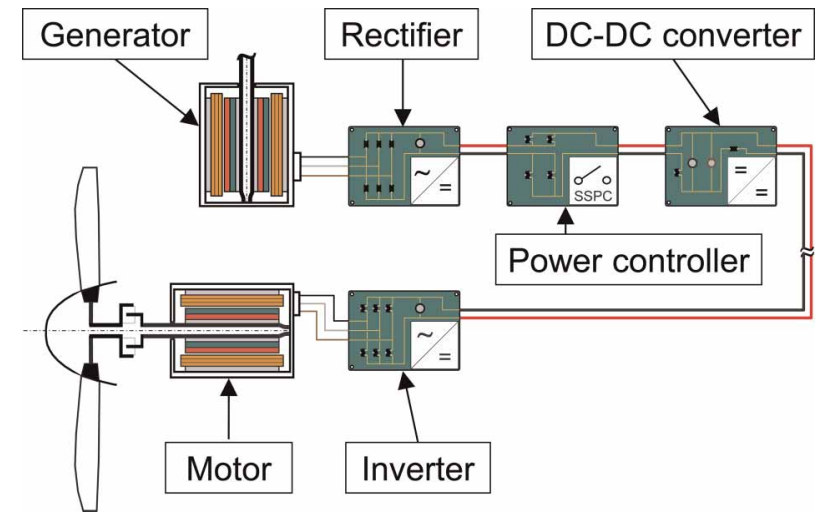

Figure 3. The components of the electric powertrain. 
low-pressure spool of the gas turbine. Since a coupling of the rotational speeds of the wingtip propeller and the gas turbine is not desired, a variable speed drive is needed.

The three-phase alternating current $(\mathrm{AC})$ produced by the generator is converted to direct current by the rectifier. The DC-DC converter then converts the voltage to the necessary voltage level for the inverter. The power electronic components are connected to each other by a DC cable. A DC power controller will work as a circuit breaker in the event of component failures. The inverter is used to convert the DC voltage into three-phase AC voltage for the electric motor. The wingtip propeller is then connected to the electric motor via a gearbox. In this way, the wingtip propeller speed is independent of the turboprop engine's low-pressure spool speed.

\section{Electric component modeling}

In order to simulate the electric powertrain, the GasTurb software is accordingly extended with the component models described below. The basic concept for the modeling of the electric components is taken from Vratny (2019).

\section{Electric machines}

Due to their power density, the generator and the motor are projected to be permanent magnet synchronous machines (PMSMs). The modeling of the electrical machines is based primarily on Müller et al. (2008). By Köhler and Jeschke (2021) specific additions were made and validated against experimental data from Vollmer (2012). In the implemented model, the required torque and speed are the primary design parameters. The electric and the magnetic loading represented by linear current density and maximum magnetic flux density, serve as input parameters to calculate the required air gap diameter of the machine. In this context, the ratio of the length of the active parts to the air gap diameter also is an input variable. Similar to the air gap diameter, the stator dimensions can be calculated from the electric and magnetic loading. Detailed explanations of the calculations can be found in the aforementioned literature. Copper is chosen as the conductor material. The influence of other conductor materials, such as aluminum or silver, is not investigated. Based on an empirical regression from Köhler and Jeschke (2021) a mean machine density of $1,200 \mathrm{~kg} / \mathrm{m}^{3}$ was anticipated for 2035, which in combination with the dimensions of the machine allows for the calculation of machine mass.

To model the operational characteristics of the machine, a map is used. This is in line with the level of detail of the calculations for turbomachinery, where no high-fidelity methods are used either. For this reason, the efficiency of the machine at the design point is an input parameter. Its value is taken from empirical values of similar machines. To calculate the voltage and the current corresponding to the torque and the speed of the operating point, an equivalent circuit is used. Further details of the operational characteristics modeling can be obtained from Köhler and Jeschke (2021).

\section{Power electronics}

The power electronics components consist of semiconductor devices such as diodes and transistors. Individual semiconductor devices can only switch limited voltages and conduct limited currents. To illustrate the modeling of the power electronic components, the rectifier depicted in Figure 4 is used as an example. Only unidirectional power transfer occurs and the generator spool speed is almost constant. As such, an uncontrolled three-phase bridge rectifier is chosen. The sizing method and the loss calculation for semiconductor devices is basically the same for all of the components. The other power electronics components of the partial turboelectric propulsion

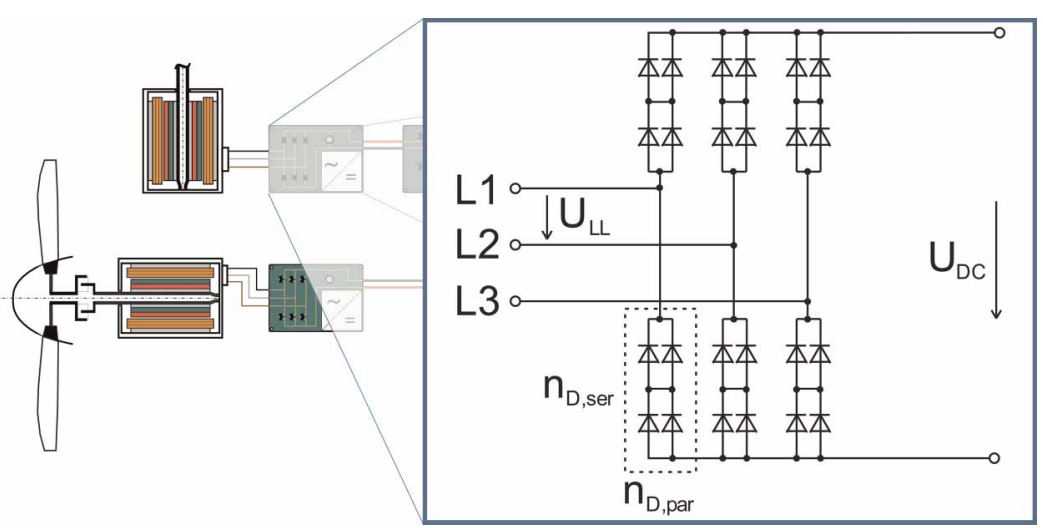

Figure 4. Circuit diagram of the rectifier. 
system are a solid-state power controller, a DC-DC buck-boost converter and a three-phase inverter. The basic current and voltage calculations in the components are conducted according to Schröder and Marquardt (2019). Semiconductor devices for power electronics are optimized for high voltage and current. Nevertheless, their capabilities are limited. If high currents, which exceed the capability of a single diode, have to be conducted several diodes must be connected in parallel. At high voltages, which exceed a single diode's capability, the diodes have to be connected in series, as shown in Figure 4. So, one of the main tasks in the component design is to determine the number of semiconductor devices in parallel and in series. The DC-DC converter additionally requires an inductor as well as capacitors at the input and output, which smooth out the voltage ripples that would otherwise occur. Having determined the number of semiconductor devices and the sizes of the inductor and the capacitors, the mass of the corresponding component is calculated. To account for additional masses, such as the masses of the casing or of the circuit board, a factor is applied. During the operation of power electronics losses occur. In the models implemented, conduction losses and switching losses are taken into account, both during design and off-design calculations. Blocking losses and driving losses have a much smaller impact in the given application and therefore are ignored. The loss modeling is based on Wintrich et al. (2015) and validated against data from SEMIKRON International GmbH (2020). Semiconductor losses depend on several different parameters. The most significant ones are current, voltage, and switching frequency at the single semiconductor device. Combining the conduction and the switching losses of a single semiconductor device and then multiplying them by the number of devices in the power electronics component, yields its total loss. At system level, the losses show up as a voltage drop. For the inverter calculation the degree of modulation, used for the pulse-width modulation, and the power factor are of additional importance. For the DC-DC converter the duty cycle, as well as additional losses caused by the inductor and the capacitors, have to be considered. The internal topology of the component is determined in the design. The defined number of semiconductor devices in parallel and in series is then taken into account in the off-design calculation (Vratny, 2019).

Due to the complexity of power electronics, several simplifications have to be made for the propulsion system performance simulation. For example, no instantaneous values of current or voltage are passed between the component models, and the temperature of the semiconductors is assumed to be constant. Utilizing the power electronics modeling, different design parameters - which both affect power electronics and electric machines-can be studied. Only in this way a meaningful holistic electric powertrain optimization can be conducted.

\section{DC cable}

A DC cable is required for transmitting the electric power between the power electronics components. The cable connecting the DC-DC converter and the inverter is several meters long. Because of its mass it has to be examined in detail. However, the cable mass is smaller than the mass of a single electric machine and the conduction losses of the cable have only a minor impact on the overall system losses. Given the electric power of approximately 1.5 MW or less, the complexity and cooling system mass of a superconducting cable do not seem to be worthwhile. Accordingly, a conventional cable is considered to be sufficient.

The conventional cable model consists of a solid conductor, a surrounding insulation and a sheath which protects the insulation. For the design, a certain current density is prescribed allowing the conductor diameter to be obtained from the current transmitted. A conductor is required for each polarity (+ and -). The insulation thickness depends on the given voltage, the conductor diameter as well as other parameters and is determined using an analytical equation from Cheng (1994). The sheath thickness is chosen according to the usual sheath thickness of similar cables. The cable mass is calculated on the basis of the diameters of the conductor, the thickness of the insulation and the sheath, the material densities, as well as the cable length. In order to calculate the cable's resistance, it is necessary to know its length and the conductor diameter. During off-design operation, the ohmic losses of the cable can be determined using the resistance value from the design calculations. Different conductor materials can be used in the cable model. However, because of disadvantages, such as higher costs or higher losses for some materials, only copper was regarded as conductor material in the investigated powertrains.

\section{Thermal management system modeling}

To manage the heat loads from the electric powertrain, a thermal management system (TMS) is required. The detailed system model consists of coldplates for heat acquisition; pipes, ducts, pumps, and fans for heat transport; and a compact heat exchanger for heat rejection. Each component is modeled to a level of detail which allows TMS mass, drag, power, and size to be assessed. The modeling procedure, as well as design and off-design studies of the TMS, have been described in detail by Kellermann et al. (2021). 
For the comparison of the baseline and the partial turboelectric aircraft, TMS masses are used. These are the final results based on an optimization towards a target function derived from the aircraft. The setup of the optimization study is also explained in detail by Kellermann et al. (2021).

\section{Preliminary partial turboelectric propulsion system design process}

This subsection describes the preliminary propulsion system design process. The preliminary design of the propulsion system is implemented using the models described in the previous subsection. Before the process itself is explained, the used electrification and performance metrics are outlined. Next, the iterative preliminary design process with its interfaces between the aircraft and the propulsion system, as well as the subordinate processes on the propulsion side, will be explained, and finally, the propulsion system's off-design operating strategy will be clarified.

\section{Electrification metric}

In order to define the degree of electrification clearly, a distinct metric is necessary. For the design of the partial turboelectric propulsion system, this key metric is the power split $S_{P}$. This describes the share of electrically driven shaft power in the propulsion system's total shaft power. $S_{P}$ is defined by Equation 1, where $P_{\text {main propeller }}$ is the design shaft power of the mechanically driven main propeller and $P_{\text {wingtip propeller }}$ is the design shaft power of the electrically driven propeller at the wingtip. The total propeller shaft power $P_{\text {total }}$ is the sum of these shaft powers.

$$
S_{\mathrm{P}}=\frac{P_{\text {wingtip propeller }}}{P_{\text {main propeller }}+P_{\text {wingtip propeller }}}=\frac{P_{\text {wingtip propeller }}}{P_{\text {total }}}
$$

In principle, the equation is applicable over the entire operating range. However, at the beginning of the design process for a partial turboelectric system, the main propeller's maximum shaft power $P_{\text {main }}$ propeller,max is not known. This occurs during takeoff conditions and is an off-design result of the turboprop engine core design and the selected $S_{P}$. To avoid dependency on an engine off-design operating point and a feedback of $S_{P}$ on itself, $S_{P}$ refers to the design power values on both propeller shafts. Full wingtip propeller power is envisaged at TOC and thus this is the design point, for both gas turbine and the electric powertrain. Taking this into account $S_{P}=0 \%$ signifies a completely conventional propulsion system and $S_{P}=100 \%$ represents a fully turboelectric propulsion system. As will be shown in the preliminary design studies, the sizing of electrical components for a given $P_{\text {total }}$ of the partial turboelectric propulsion system depends to a substantial degree on $S_{P}$.

As power specific fuel consumption PSFC is a key performance metric for turboprop engines, analogous to it,

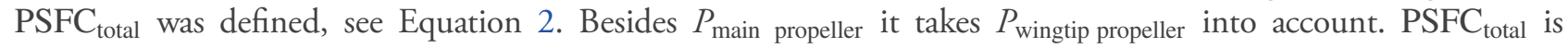
defined as the fuel flow of the main engine $\dot{m}_{\text {fuel }}$ divided by the total shaft power $P_{\text {total }}$.

$$
\mathrm{PSFC}_{\text {total }}=\frac{\dot{m}_{\text {fuel }}}{P_{\text {main propeller }}+P_{\text {wingtip propeller }}}=\frac{\dot{m}_{\text {fuel }}}{P_{\text {total }}}
$$

\section{Iterative aircraft and propulsion system design}

Properly matching the aircraft and the propulsion system ensures that the propulsion system can fulfill its requirements, while at the same time not being unnecessarily heavy. At the start of the design process, the exact size and mass of both the baseline and the partial turboelectric aircraft are not known. For this reason, empirical values for the baseline aircraft and its propulsion system are used to perform initial mission calculations. After a few iterative calculations, involving the propulsion system mass and dimensions, the shaft power requirements of the conventional turboprop baseline aircraft can be determined.

For the partial turboelectric aircraft, the design process is more complex, due to additional degree of freedom in $S_{P}$ as well as the initially unknown influences of the wingtip propellers and the electric components. An iterative design process for the partial turboelectric propulsion system was therefore established, which is described below. In a simplified form it is visualized in Figure 5. The upper half of the flow chart shows the process on the aircraft side, where the final baseline turboprop aircraft design is used as the starting point. The lower half of Figure 5 shows the propulsion system side. The center line marks the interface, where the information is shared between the two subordinate processes. For the propulsion system design, the baseline aircraft's engine is used as the starting point. The combined shaft power of the main propeller and the wingtip propeller has to be taken 


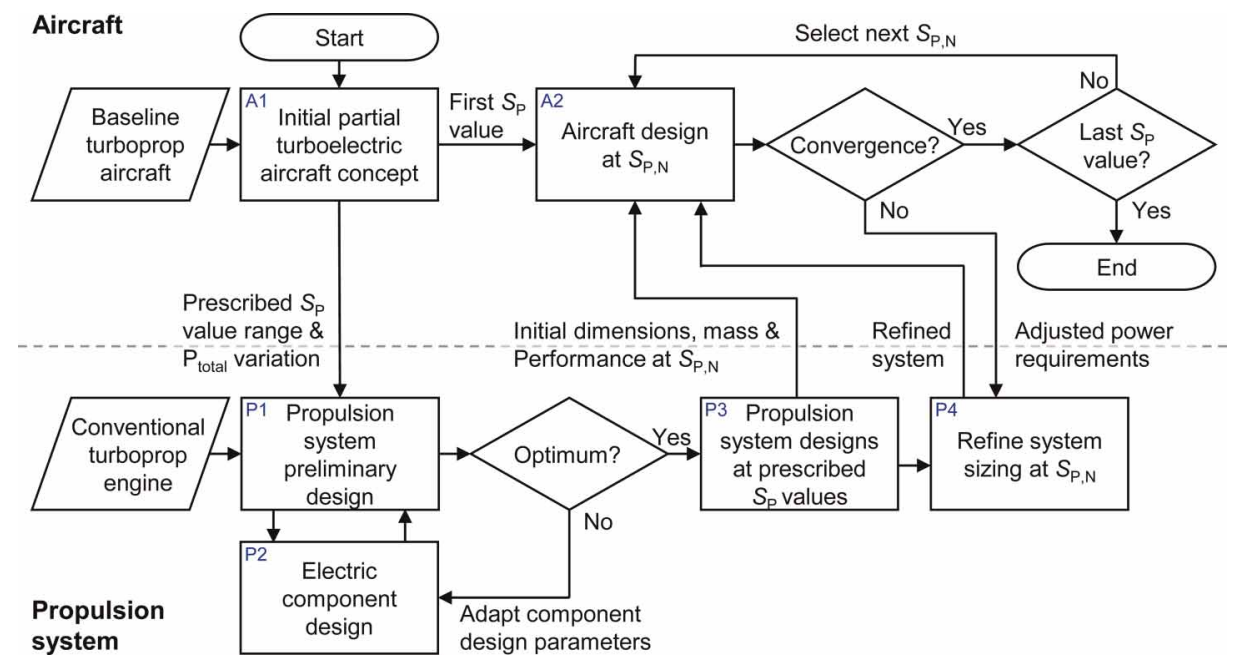

Figure 5. Flow chart of the partial turboelectric aircraft propulsion system design process.

into account in the partial turboelectric propulsion system. Due to the intended reduction of the induced aircraft drag, the combined propeller shaft power is expected to be slightly lower than the baseline shaft power requirement value. In order to estimate the influence of $S_{P}$ on system mass and $P_{\text {total }}$, preliminary design studies for the partial turboelectric propulsion system are conducted, see lower part of Figure 5 (P1). The studies were carried out with the modified GasTurb version and will be described in detail in the next section. For these studies, the aircraft design process, see upper part of Figure 5 (A1), provides an array of distinct $S_{P}$ values to the propulsion system design. Additionally, two variants of the baseline shaft power requirement are needed by the aircraft design. In other words, a turboprop engine design with a shaft power, which is a certain percentage above the baseline shaft power requirement, and a design with the same percentage below the baseline value are provided. Based on both of these engines, partial turboelectric propulsion systems are also designed. When this data is considered, trade factors for the propulsion system can be derived. The optimum electric component design (P2), regarding mass and efficiency, depends on the actual power the component has to transmit. The component design, in turn, affects the adjacent components and thus the whole powertrain. This means that an iterative approach is necessary for the electric powertrain design. For each optimized propulsion system at a prescribed $S_{P}$ value (P3), the design results for masses, fuel mass flows, and dimensions are transferred to the aircraft design. Additionally, the off-design decks (see off-design operating strategy below) for the medium $P_{\text {total }}$ propulsion systems are given to the aircraft design process.

At distinct $S_{P}$ values (e.g., $S_{P, 1}=10 \%, S_{P, 2}=20 \%$ etc.), the aircraft is designed using the propulsion system data (A2). This includes the TMS, see Kellermann et al. (2021). The aircraft design is optimized for minimum block fuel consumption and its compatibility with the propulsion system is checked. If the propulsion system does not match the aircraft design, $P_{\text {total }}$ will be adapted in an iterative way to match exactly the partial turboelectric aircraft's requirement at the given $S_{P}(\mathrm{P} 4)$. To achieve this, the different designs of the propulsion system previously provided are interpolated. The off-design deck with $S_{P, N}$ is scaled accordingly. For the final mission calculation, a specific off-design deck, corresponding exactly to the $P_{\text {total }}$ value, is provided. When the aircraft design at $S_{P, N}$ is converged, the design process for $S_{P, N+1}$ is started until all prescribed $S_{P}$ values are covered. Next, some aspects which are specific to the partial turboelectric propulsion systems are explained in further detail.

\section{Gearbox sizing}

The propeller gearbox is an essential part of a turboprop propulsion system and has a significant mass. In a partial turboelectric propulsion system, additional gearboxes might be beneficial despite their masses. The benefit of these gearboxes and the sizing strategy of the main propeller gearbox are discussed here. The mass correlates to a considerable extent with the mechanical power which can be transmitted by the gearbox. To calculate the mass of the gearboxes, a correlation from NASA (Brown et al., 2005) is used.

\section{Wingtip propeller gearbox}

The propeller speed depends on its diameter, since the blade tip speed is limited. Raising the motor speed significantly above the propeller speed results in a major reduction in motor mass, which overcompensates the 
additional gearbox mass. To achieve maximum power density, the optimum motor speeds are often much higher than the feasible propeller speeds. This aspect will be investigated in more detail in the design studies section. For this reason, a gearbox is also used on the wingtip propeller, and the motor speed becomes a design variable. The same mass correlation is applied as for the main propeller gearbox.

\section{Potential generator gearbox}

When combining propellers with either electric motors or turbines, using a gearbox is often advantageous. As for electric motors, high speeds are beneficial for the generator's power density. In this regard, the optimum generator design speed would be higher than the low-pressure spool speed, but losses in the electric powertrain increase with higher speed. For this paper therefore, the generator is directly mounted to the spool, omitting the generator gearbox as well as its mass and losses.

\section{Main propeller gearbox}

The main propeller gearbox is sized to the operating point with the highest mechanical load. This load occurs at sea level static conditions and is prescribed by the takeoff power requirement. In some operating points therefore, the gearbox limits the maximum power of the gas turbine, or more precisely its torque.

In the case of a partial turboelectric propulsion system, the main propeller gearbox sizing strategy attains additional importance. The question arises as to whether the main engine gearbox should be capable of transmitting the whole gas turbine power in the event of a failure in the electric powertrain. This question also applies to the propeller, since it has to be capable of producing additional thrust from the extra power. For this paper, the main propeller and its gearbox do not include back-up potential for the failure of the electric powertrain, because it is not as critical as the failure of the gas turbine itself.

\section{Electric powertrain}

After having discussed the general design process for the propulsion system and the gearbox sizing, the electric powertrain design process is brought into focus. A brief description of the design calculation algorithm in the tool is given next, which is then followed by a short explanation of the off-design calculation algorithm.

\section{Electric powertrain design calculation algorithm}

The electric powertrain design is carried out analogously and virtually parallel to the gas turbine design. In the case of the electric powertrain, electric properties, such as resistances, inductances, and capacitances, as well as component masses, are determined. During the design phase, the electric powertrain is considered independently from the gas turbine, that is, the design power off-take of the gas turbine does not necessarily have to match the design generator power.

Each component in the electric powertrain, see Figure 3, is sized for the system's maximum continuous power, taking into account maximum currents and voltages. The design calculation starts with the electric motor. The speed and torque of the electric motor are the input parameters which define the required mechanical power. Subsequently the other components of the electric powertrain are sized according to this initial maximum power requirement, taking into account the accompanying losses.

For the loss calculations of the inverter and the rectifier, $\mathrm{AC}$ voltage properties are necessary. For this reason, the generator design calculation has to be performed before the exact power required is known. An iteration is applied to ensure that the electric powertrain's internal power balance is fulfilled. The generator speed is a fixed input parameter during the design calculation. For this reason, the generator's torque is varied during the design iteration process in order to match the motor's power demand. For the propulsion system under investigation, the generator design speed is the same as the gas turbine's low-pressure design spool speed. This seems advantageous for the generator mass and for the off-design performance, since most of the time the spool operates at the design speed.

\section{Electric powertrain off-design calculation algorithm}

The power off-take at the gas turbine's low-pressure spool at a certain operating point is predetermined through the off-design operating strategy of the partial turboelectric propulsion system (see paragraph below). With the given power off-take and the known low-pressure spool speed, the generator torque and speed can be calculated. The electric motor speed is an input, since a variable pitch propeller is used. The wingtip propellers are operated at constant speed. Hence, the motor speed is constant as well. The motor torque is iterated to determine the power balance of the electric powertrain, including the electric transmission losses of the system. 


\section{Propulsion system off-design operating strategy}

To optimize the use of the aerodynamic advantage of the wingtip propeller, it is operated at its maximum continuous power rating, whenever it is possible. Analogous to Equation 1, the power split at any off-design operating point $S_{\mathrm{P}, \text { off-design }}$ can be described as:

$$
S_{P, \text { off-design }}=\frac{P_{\text {wingtip propeller,off-design }}}{P_{\text {main propeller,off-design }}+P_{\text {wingtip propeller,off-design }}}=\frac{P_{\text {wingtip propeller,off-design }}}{P_{\text {total,off-design }}}
$$

However, there are operational limitations to $S_{P, \text { off-design. At ambient conditions or part loads, the advanced }}$ turboprop engine's power might be lower than the generator's design power. To prevent the generator from stalling the engine, the power drawn by the electric powertrain has to be limited. This can be done by limiting the $S_{P, \text { off-design value to }} S_{P}$. In addition, it must be possible to guarantee safe operation of the electric system. If the advanced turboprop engine produces a higher power than in the design point, the electric powertrain is limited to its maximum continuous power rating. The target value of $S_{P, \text { off-design }}$ is determined as:

$$
S_{P, \text { off-design }}=\min \left[S_{P} ; \frac{P_{\text {generator,mech.,max }}}{P_{\mathrm{LPT}, \text { off-design }} \cdot \eta_{\text {low-pressure spool,mech. }}}\right]
$$

This is implemented by constantly monitoring the ratio of the maximum mechanical input power of the generator $P_{\text {generator, mech., max }}$ and the product of low-pressure turbine power $P_{\mathrm{LPT} \text {,off-design }}$ and the mechanical efficiency of the low-pressure spool $\eta_{\text {low-pressure spool,mech. }}$. While $P_{\text {generator,mech.,max }}$ is constant, the value of the denominator increases with rising $P_{\mathrm{LPT}, \text { off-design }}$ and lowers the acceptable $S_{\mathrm{P}, \text { off-design }}$ value.

\section{Preliminary propulsion system design studies}

Several parametric studies have been carried out for the partial turboelectric aircraft, the TMS, and the partial turboelectric propulsion system. These were conducted to constrain the respective parameter space and to identify possible optima. For the detailed TMS studies please refer to Kellermann et al. (2021). This section presents results of the studies of the partial turboelectric propulsion system as a stand-alone system not including the TMS. Since it is also a crucial part of the partial turboelectric propulsion system, the design studies for the turboprop engine are included as well. In the graphs below, the baseline parameter values are marked with black crosshairs.

\section{Preliminary design of the conventional turboprop engine}

To achieve a high thermal efficiency, a high overall pressure ratio is required. To this end, a three-shaft configuration with a free-running low-pressure turbine driving the propeller was chosen for the turboprop engine. Using data from existing turboprop engines from Jane's Aero Engines (Daly, 2014) and the basic principles of gas turbine design from Walsh and Fletcher (2008) and Grieb (2004), the preliminary design for a current threeshaft turboprop was made. Based on this design, the engine design was adapted to the requirements and entry into service for the reference engine in an iterative process.

\section{Turbomachinery components}

The polytropic efficiencies applied in the final 4,135 kW TOC-power model are shown in Figure 6. The HPC type is not prescribed. It might be strictly axial, as in the Europrop International TP400-D6 turboprop engine, or axial with a final radial stage, comparable to the Ivchenko-Progress D-27 engine (Daly, 2014). The selection depends primarily on the compressor pressure ratio and the mass flow. For decreasing volumetric flow rates, a slight decrease in the HPC efficiency is stipulated. Apart from this, the issue is not examined in any further detail during the preliminary design.

\section{Thermodynamic cycle}

The turbomachinery efficiencies are only valid for a narrow range of mass flows and pressure ratios, so by employing the corresponding efficiencies, the thermodynamic cycle is optimized iteratively. While TOC is the design point of the gas turbine, it is mainly operated under cruise conditions throughout the mission. The engine's fuel consumption during cruise is therefore crucial. Figure 7 shows the mid-cruise PSFC dependency on 


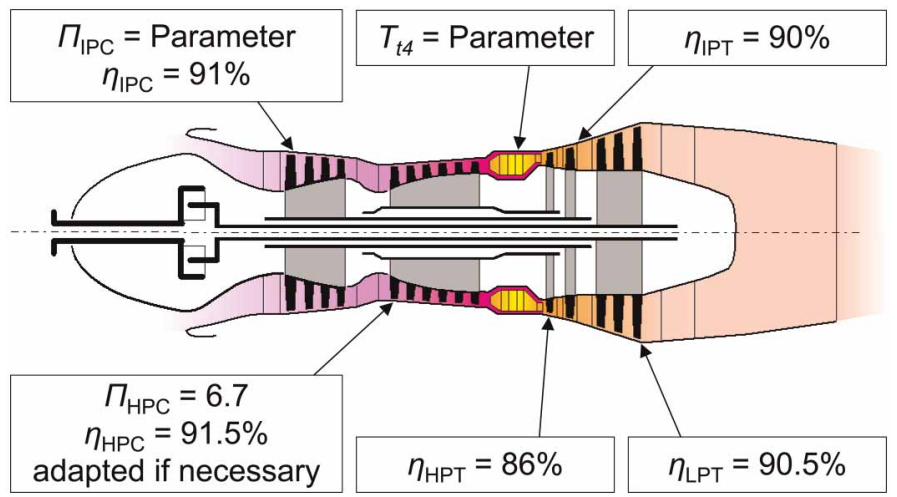

Figure 6. Polytropic efficiencies and pressure ratios of the intermediate (IPC) and the high-pressure compressor (HPC) and polytropic efficiencies of the high (HPT), intermediate (IPT) and low-pressure turbine (LPT) for the gas turbine design.

overall pressure ratio and the burner exit temperature $T_{t 4}$ at the design point. The component efficiencies remain constant for this plot. While Figure 7 indicates a further modest decrease in PSFC at overall pressure ratios above 36, a decrease in HPC efficiency in this region shifts the actual optimum to the left. So, with the given component efficiencies and cooling mass flows, the combination of an overall pressure ratio of 33 and a $T_{t 4}$ of $1,650 \mathrm{~K}$ has been chosen. The effects of deterioration during the service life of the engine have not been examined. After the thermodynamic cycle has been optimized, the inlet mass flow is adjusted slightly to the exact power requirement of the baseline turboprop engine at TOC, see Table 2.

\section{Baseline aircraft shaft power requirements}

The following section describes the requirements for one of the aircraft's two engines. The shaft power requirement at TOC is shown in the first row of Table 2. The mid-cruise power requirement is shown in the second row. As far as the power is concerned, the mid-cruise requirement can be easily fulfilled by the engine. This requirement amounts to only $72.4 \%$ of the TOC value at a $2.9 \%$ higher altitude. Another important operating point is takeoff, where the highest power demand occurs. Full takeoff power has to be provided at hot-and-high conditions, as indicated in the third row of Table 2. Due primarily to the torque capacity of the propeller gearbox, even at lower altitudes and temperatures, the shaft power of the gas turbine is limited to the value given in Table 2.

\section{Preliminary design of the partial turboelectric propulsion system}

As explained in the methodology section, the baseline aircraft's conventional turboprop engine represents the starting point for the preliminary design of the partial turboelectric propulsion system. This means that the final

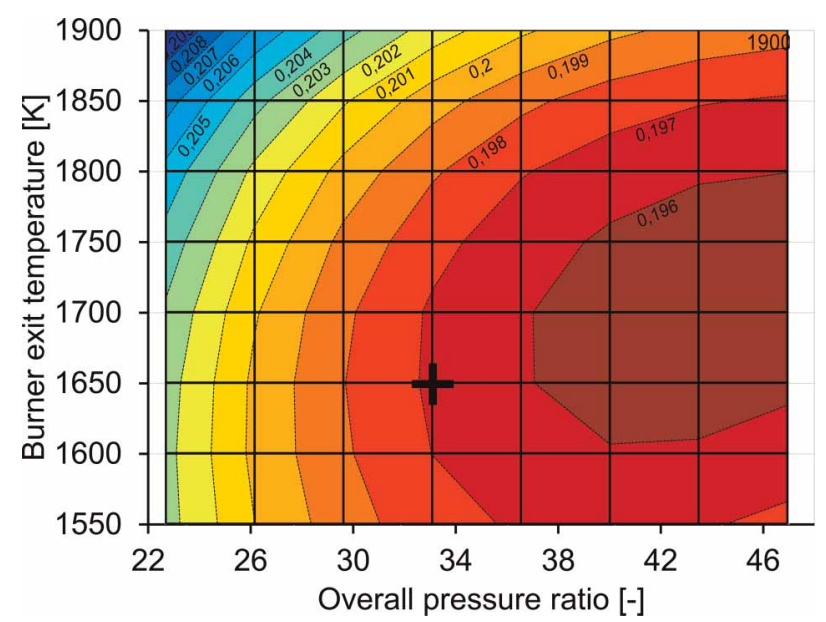

Figure 7. PSFC $[\mathrm{kg} / \mathrm{kWh}]$ in mid-cruise as a function of overall pressure ratio and burner exit temperature $T_{t 4}$ at the design point; grid aligned according to parameter variation. 
Table 2. Iteratively determined shaft power requirements at the operating points top of climb (TOC), mid-cruise, and hot day takeoff (HDTO) and the corresponding altitude, temperature deviation from the international standard atmosphere (ISA), and flight Mach number.

\begin{tabular}{|l|l|l|l|l|}
\hline Operating point & Altitude & $\Delta T_{\text {ISA }}$ & Mach number & Shaft power requirement \\
\hline TOC & $10,668 \mathrm{~m}$ & $+10 \mathrm{~K}$ & 0.68 & $4,135 \mathrm{~kW}$ \\
\hline Mid-cruise & $10,973 \mathrm{~m}$ & $+10 \mathrm{~K}$ & 0.68 & $2,992 \mathrm{~kW}$ \\
\hline HDTO & $1,524 \mathrm{~m}$ & $+20 \mathrm{~K}$ & 0.2 & $7,474 \mathrm{~kW}$ \\
\hline
\end{tabular}

baseline turboprop core engine is used as the initial advanced turboprop core engine for one half of the partial turboelectric propulsion system. As such, for the propulsion system studies in this section, the advanced turboprop engine's $P_{\text {LPT }}$ remains the same as for the baseline turboprop engine. Next, a presentation is given of the preliminary partial turboelectric propulsion system design studies at overall system level and then at the component levels.

\section{Overall system level}

The key system design variable of the partial turboelectric propulsion system is $S_{P}$. This variable's importance has already been outlined in the preliminary design process section and its influence will now be explained in greater detail.

The main benefit of increasing $S_{P}$ above $0 \%$ is the reduction of induced drag. While this benefit is achieved in most of the operating points, the largest mission fuel burn savings are expected from drag reductions in the cruise segment. Therefore, only $S_{P}$ values as low as $10 \%, 20 \%$ and $30 \%$ were investigated in this study. Higher values of $S_{P}$ would result in heavy electric systems which could outweigh the aerodynamic benefits. Only a presentation of the final results of the studies at propulsion system level, including the optimized component designs, is given here.

The quantities in Figure 8 are plotted over $S_{P}$. The change in mass of the isolated partial turboelectric propulsion system results from the additional mass of the electric powertrain combined with the decreasing mass of the main propeller gearbox. Regarding the relative change of $P_{\text {total }}$, it should be borne in mind that the advanced turboprop engine's $P_{\mathrm{LPT}}$ is held constant. The linear course of the graph is a result of the fact that the efficiency of the electrical system is almost constant and does not increase with system size. The cause of the decreasing $P_{\text {total }}$ are the losses occurring in the electric powertrain. The constant core engine power is accompanied by a

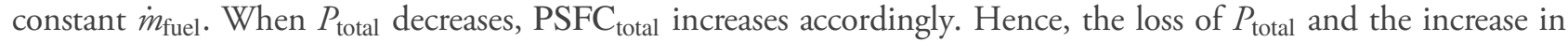
$\mathrm{PSFC}_{\text {total }}$ are proportional to each other. After taking into consideration the general trends which apply for any

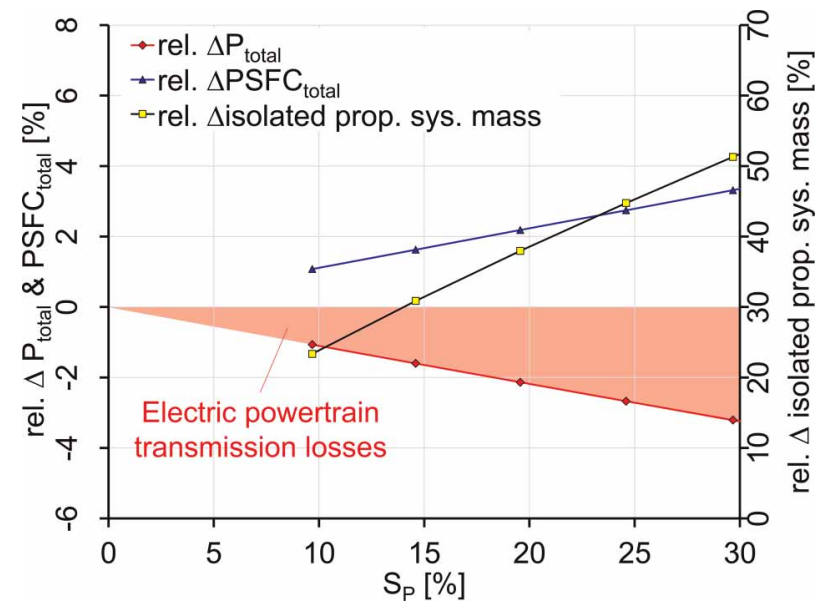

Figure 8. Relative $\Delta P_{\text {total, }}$, relative $\Delta \mathrm{PSFC}_{\text {total }}$ and relative $\Delta$ of the mass of the isolated partial turboelectric propulsion system compared to the conventional $4,135 \mathrm{~kW}$ baseline engine over $S_{P}$ at top of climb. 
Table 3. Shaft powers and PSFC $_{\text {total }}$ of the partial turboelectric propulsion system at top of climb.

\begin{tabular}{|l|l|l|l|l|}
\hline$S_{P}$ & $P_{\text {main prop. }}$ & $P_{\text {wingtip prop. }}$ & $P_{\text {total }}$ & PSFC $_{\text {total }}$ \\
\hline$\%$ & $\mathrm{~kW}$ & $\mathrm{~kW}$ & $\mathrm{~kW}$ & $\mathrm{~kg} / \mathrm{kWh}$ \\
\hline 0 & 4,135 & 0 & 4,135 & 0.1859 \\
\hline 10 & 3,680 & 409 & 4,089 & 0.1879 \\
\hline 20 & 3,236 & 809 & 4,045 & 0.1900 \\
\hline 30 & 2,801 & 1,200 & 4,001 & 0.1921 \\
\hline
\end{tabular}

partial turboelectric propulsion system, Table 3 shows the actual power and $\mathrm{PSFC}_{\text {total }}$ for the partial turboelectric

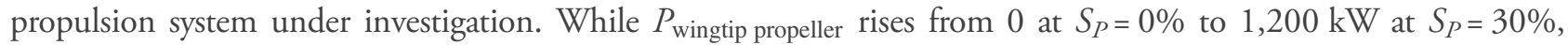
$P_{\text {total }}$ drops from $4,135 \mathrm{~kW}$ to $4,001 \mathrm{~kW}$. These values will later be compared to the results at aircraft level.

Figure 9 shows masses of the individual electric powertrain components over $S_{P}$. All component masses rise primarily proportional to $S_{P}$. The electric machines have the largest share of the system mass, followed by the gearbox of the wingtip propeller and the DC cable. The remaining amount of the electric system mass consists of the power electronics components, with the inverter having the largest share. If the electric components are completely omitted, there is a discontinuity in the system mass, since some components already have a certain mass, even if they transfer very low power. For the component level discussions, $S_{P}=30 \%$ is used, but the component design process is similar for all $S_{P}$ values.

\section{Electric machines}

The newly developed tool enables the user to optimize the electrical system to the same level of detail as the gas turbine. In order to demonstrate this by way of example, the studies on the electric machines will be discussed in more detail below.

The first study concerns the optimum design speed. Generally, higher speeds of electric machines lead to higher power densities which are desirable for airborne applications. Nonetheless, as speed increases, mechanical losses and stresses grow. Publications in the field of electrical machines have addressed the design limitations. For example, a PMSM with a maximum rotor circumferential velocity of approximately $180 \mathrm{~m} / \mathrm{s}$ was described by Binder and Schneider (2007). This value is regarded as the upper limit and should not be exceeded during the electric machine design. At even higher speeds, the safe fixture of the magnets can no longer be ensured, at least for inrunner machines.

For the electric machine design several parameters have to be determined. The baseline key design parameters are shown in Table 4. Electric loading, maximum current, and flux density depend on the materials and the

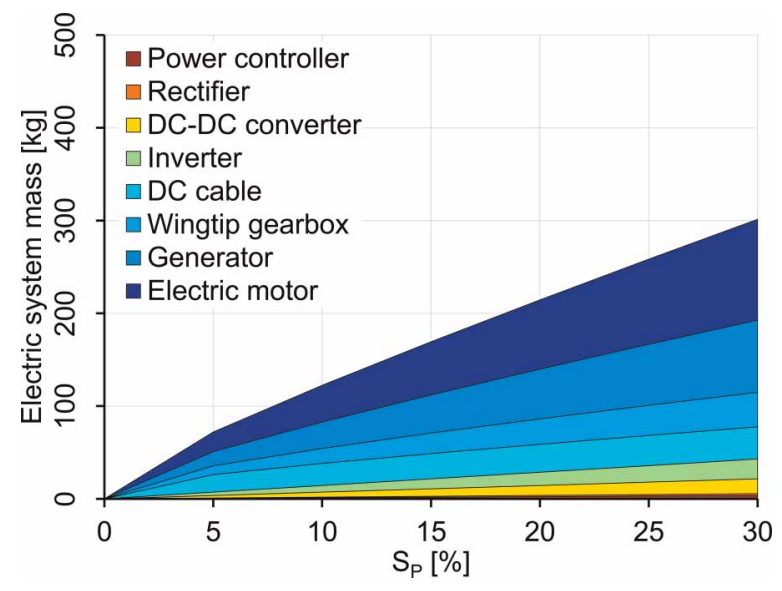

Figure 9. Masses of the electric components as a function of $S_{p}$, gas turbine power remaining constant. 
Table 4. Electric machine baseline key design parameters.

\begin{tabular}{|l|l|}
\hline Parameter & Value \\
\hline Electric loading & $38 \mathrm{kA} / \mathrm{m}$ \\
\hline Max. current density & $7 \mathrm{~A} / \mathrm{mm}^{2}$ \\
\hline Max. flux density & $1.4 \mathrm{~T}$ \\
\hline Copper fill factor & 0.33 \\
\hline Winding factor & 0.945 \\
\hline Power factor & 0.82 \\
\hline Design efficiency & Motor: $96.5 \%$ \\
\cline { 2 - 3 } & Generator: $96.0 \%$ \\
\hline Design speed & Motor: 6,000 RPM \\
\cline { 2 - 3 } & Generator: 7,200 RPM \\
\hline Number of pole pairs & 10 \\
\hline \multirow{2}{*}{ Active length to air gap diameter ratio } & 1 \\
\hline
\end{tabular}

cooling technology used (Müller et al., 2008). The copper fill factor and the winding factor depend on the winding technology used. For the power factor, which can be varied in a small range, an empirical value is used. Since detailed efficiency calculations for the machines require high fidelity methods, the design efficiency is an empirical input value. The active length to air gap diameter, the number of pole pairs, and the design speed can be varied across a wide range.

Only the motor will be examined in this first electric machine study, but the same approach basically applies for the generator. The propeller speed is obtained by using a prescribed power loading of the propeller and a given maximum tip Mach number. Taking into account the propeller gearbox losses, the mechanical power of the electric motor can be calculated from Table 3. For $S_{P}=30 \%$ the value is $1.21 \mathrm{MW}$. Starting from the baseline parameters, the number of pole pairs and the design speed are varied. The results are shown in Figure 10. For the mechanical power of 1.21 MW and the parameters from Table 4 at 9,000 RPM, a rotor circumferential velocity of $180 \mathrm{~m} / \mathrm{s}$ is reached, which marks the upper speed boundary of the study. 3,000 RPM, which is a standard speed for $50 \mathrm{~Hz}$ grid applications, marks the lower speed limit. At least one pole pair is needed in an electric motor. Because of the strong increase of system mass when applying a low number of pole pairs, a lower boundary of two pole pairs is chosen. When only Figure 10 is considered, the speed and number of pole pairs should be as high as possible. At the same time, Figure 11 shows that higher speed and higher number of pole pairs lead to lower efficiencies. The reason for this is the increasing electric frequency, which results in higher power electronic losses. Thanks to the high efficiency level of the silicon carbide ( $\mathrm{SiC}$ )-power electronics used, this effect is not very pronounced. The higher the speed and number of pole pairs, the smaller the gradient of the mass becomes. This leads to a rather conservative compromise in the selected speed of 6,000 RPM and number of pole pairs of 10, resulting in a power-to-weight ratio of $11.0 \mathrm{~kW} / \mathrm{kg}$ for the motor. In 2019, Siemens AG built a $2 \mathrm{MW}$ machine prototype for airborne application with $261 \mathrm{~kg}$ mass and a speed of 6,500 RPM (Anton, 2019), yielding a power-to-weight ratio of $7.7 \mathrm{~kW} / \mathrm{kg}$. Integral Powertrain Ltd considers a peak power density of $45 \mathrm{~kW} / \mathrm{kg}$ to be feasible with high-speed machines (Integral Powertrain Ltd, 2020). Nevertheless, further research and development are needed to achieve the anticipated value for a certified machine in 2035. The high power-to-weight ratio of the projected motor might be achieved by increasing the active length to air gap diameter ratio and, with it, viable motor speeds. 


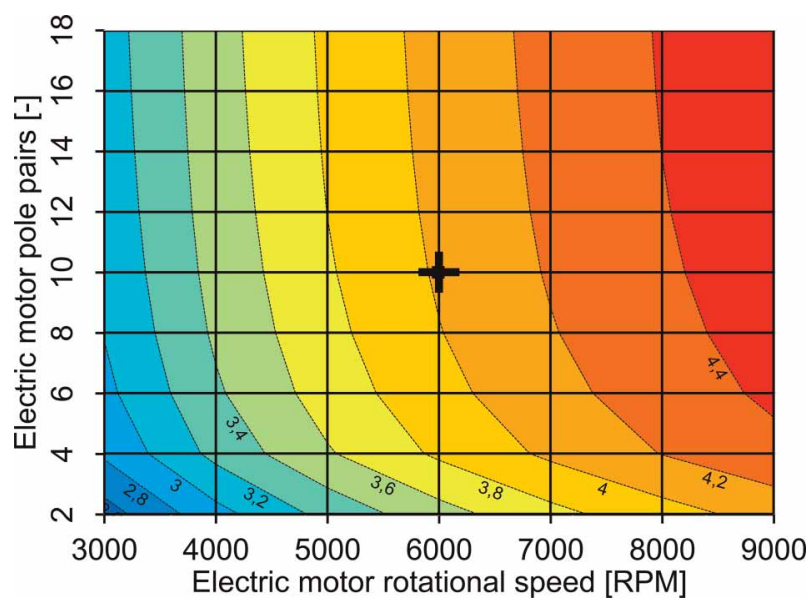

Figure 10. Combined power density of the electric system and the gearbox $[\mathrm{kW} / \mathrm{kg}]$ as a function of the rotational speed and the number of pole pairs of the electric motor $\left(S_{P}=30 \%\right.$, DC voltage at inverter inlet and motor efficiency remaining constant).

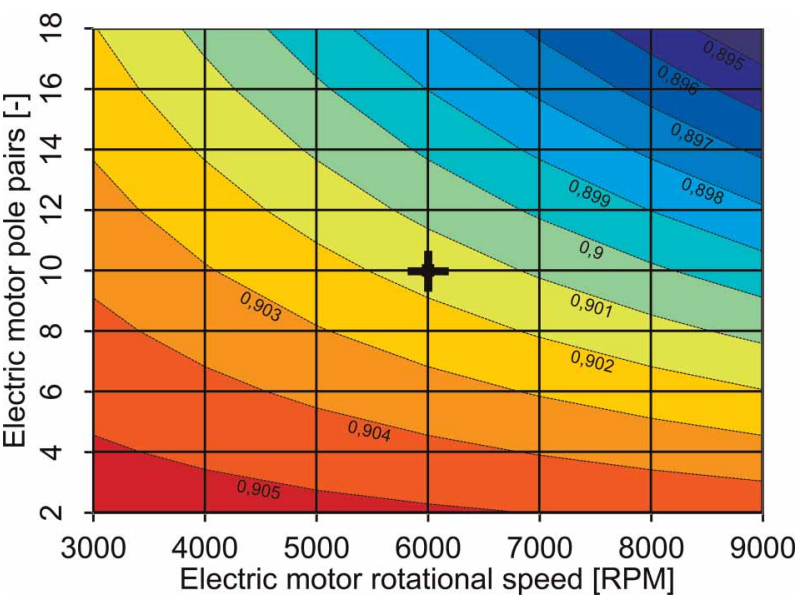

Figure 11. Electric system transmission efficiency as a function of the rotational speed and the number of pole pairs of the electric motor $\left(S_{P}=30 \%\right.$, DC voltage at inverter inlet and motor efficiency remaining constant).

The second study concerns the system voltage level. The generator output voltage depends on the parameters in Table 4, as well as the generator's number of turns in the winding. In a single-tooth winding, the individual teeth of the stator of the electric machine are wound into a coil using an insulated wire. The number of turns in the coils of electrical machines can be used to adjust the system voltage without changing other machine design parameters. This also applies to a distributed winding. Regarding the number of turns, there is an optimum ratio between the generator and the motor. This can be seen in Figure 12, where the combined power density of the electric system and the propeller gearbox is plotted over the number of turns in the machines. The ratio is optimal when the DC-DC converter has to adjust the voltage between the generator section and the motor section of the electric powertrain as little as possible. This is advantageous, both in terms of system mass and electrical transmission efficiency, see Figure 13, so that the two optima coincide. In principle, a high voltage is beneficial with regard to the system mass. However, according to Wortmann (2018) at approximately $4,000 \mathrm{~V}$ the insulation effort is starting to drastically increase. This also affects the cooling of the electric machines and power electronics. Therefore, the maximum permissible DC voltage was limited to $3,800 \mathrm{~V}$ for the preliminary design.

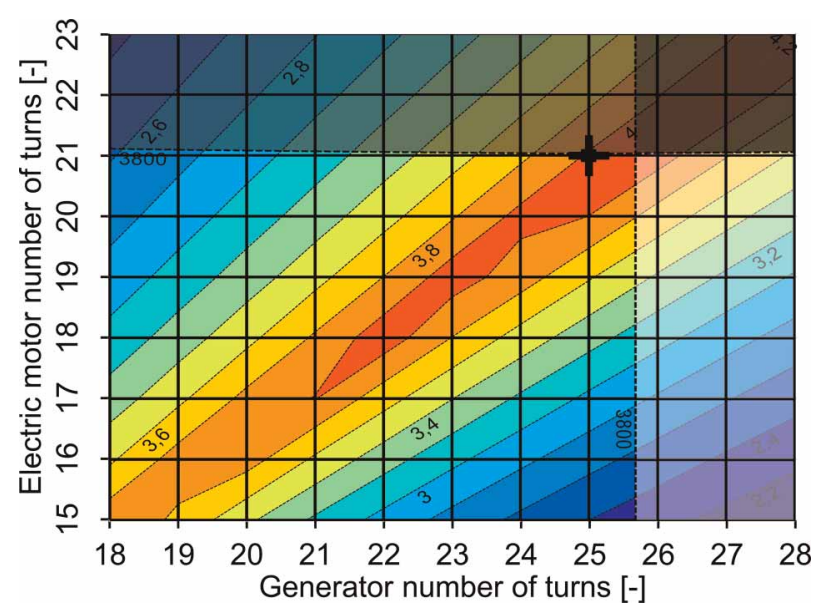

Figure 12. Combined power density of the electric system and the gearbox $[\mathrm{kW} / \mathrm{kg}$ ] as a function of the number of turns in the generator and of the number of turns in the electric motor $\left(S_{P}=30 \%\right)$; limited by $3,800 \mathrm{~V}$ DC voltage.

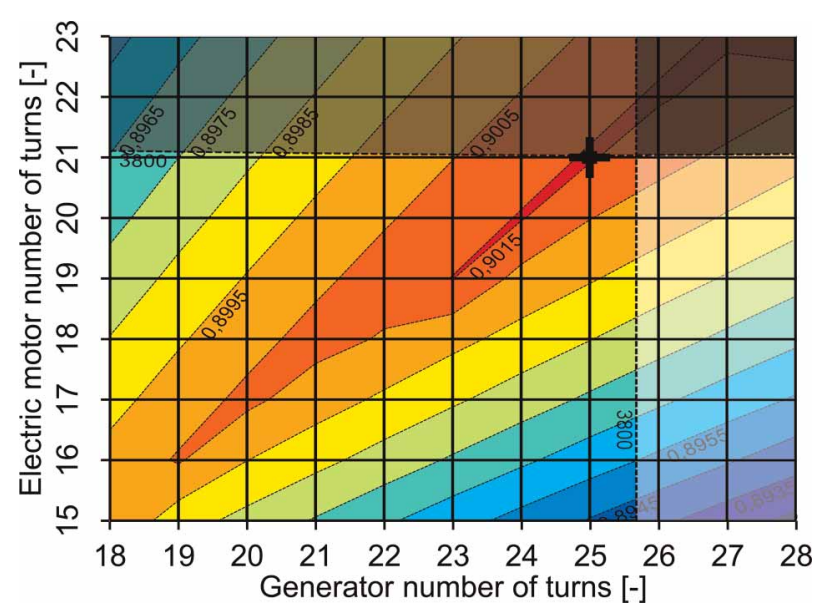

Figure 13. Electric system transmission efficiency as a function of the number of turns in the generator and of the number of turns in the electric motor $\left(S_{P}=30 \%\right)$; limited by $3,800 \mathrm{~V}$ DC voltage. 


\section{Power electronics and DC cable}

For the power electronics, SiC-semiconductor devices are assumed, since they cause significantly lower losses than purely silicon-based semiconductor devices. Therefore, each power switch is an SiC-based metal-oxidesemiconductor field-effect transistor (MOSFET). As an example, which also covers the other power electronics components, the key design parameters of the DC-DC converter are shown in Table 5. The semiconductor device parameters, such as maximum voltage, maximum current, energy losses and resistances, are chosen according to a Wolfspeed 1,200 V, 425 A, Half-Bridge Module (Cree Inc., 2020).

The same MOSFETs and diodes are used in the inverter. For the inverter, the frequency sampling factor, which describes the ratio of switching frequency and electric frequency is important. A value of 15 is applied for the sampling factor. For the rectifier, only diodes and for the power controller, only MOSFETs are needed. The total masses of the components depend on several additional parts of the component, e.g., the housing. The component mass modeling is calibrated to the Siemens SD104 inverter, which uses a micro channel cooling plate (Siemens, 2018). Studies for the power electronics, e.g., in respect of the optimum switching frequency of the DC-DC converter, are carried out. Their results are used in the component design and system optimization. For the sake of brevity, studies relating to power electronics for propulsion purposes will be released in future publications.

For the DC cable, a direct connection of the inverter close to the wingtip propeller and the DC-DC converter near the advanced turboprop on each wing is projected. This results in a cable length of approximately $10 \mathrm{~m}$. For handling the failure of a single gas turbine (one engine inoperative) an electric cross feed, connecting the advanced turboprop to the wingtip propeller on the other wing, would be advantageous. However, cross feed was outside the scope of this paper and therefore was not investigated.

\section{Comparison of the baseline and the partial turboelectric aircraft}

Having completed the preliminary design studies of the propulsion system, corresponding studies of the aircraft -incorporating the propulsion system designs — were carried out. This section presents the relationships between the propulsion system and the associated effects on the aircraft and vice versa.

The unique design feature of the partial turboelectric propulsion system is the utilization of wingtip propellers, which reduce the aircraft's induced drag and consequently the power required from the propulsion system. To illustrate the influence of the wingtip propellers, Figure 14 shows the different partial turboelectric propulsion system thrust components $T_{\mathrm{i}}$ at TOC relative to the baseline aircraft overall thrust $T_{\text {aircraft,baseline for increasing } S_{\mathrm{P}}}$ values. For $S_{P} \neq 0 \%$, the total thrust required by the aircraft $T_{\text {aircraft }}$ equals the total thrust generated by the propulsion system $T_{\text {total }}$ and the induced thrust generated by the wingtip propellers $T_{\text {induced }}$ based on the relationships derived by Loth and Loth (1984). $T_{\text {total }}$ is the sum of the thrust provided by the main propellers

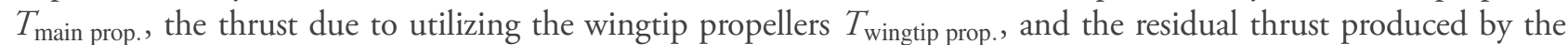
gas turbines. As the residual thrust is small and decreasing very moderately, it is not shown in the figure. The air-

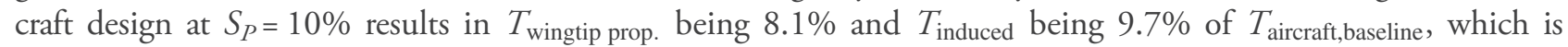
worth noting as the thrust created by the wingtip propellers themselves is smaller than the thrust created due to

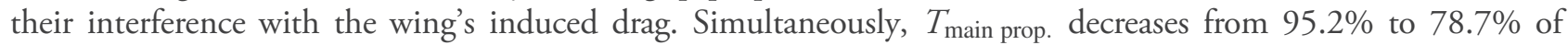
$T_{\text {aircraft,baseline }}$. Regarding the entire aircraft, $T_{\text {aircraft }}$ is slightly increased to $100.6 \%$ of the baseline aircraft's value, primarily due to the additional drag caused by the nacelles of the wingtip propellers, which overcompensates the smaller sized propulsion system, respectively aircraft. The subtraction of $T_{\text {induced }}$ from $T_{\text {aircraft }}$ finally leads to

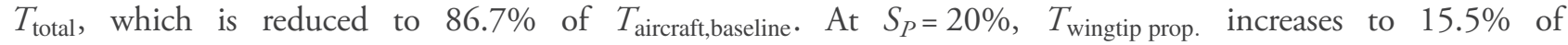

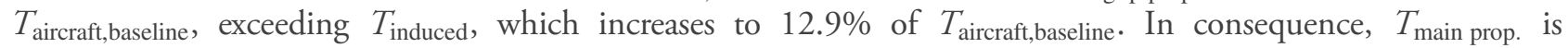

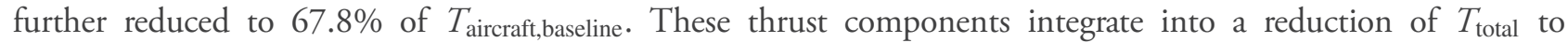

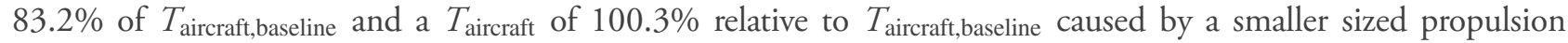

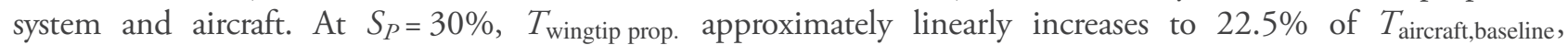

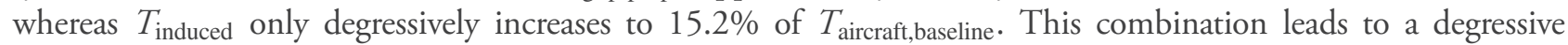

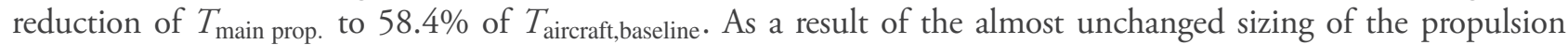
system and aircraft, $T_{\text {aircraft }}$ is eventually only negligibly decreased to $100.2 \%$ of the baseline aircraft's value.

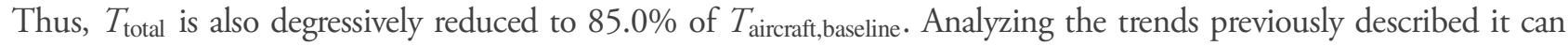
be concluded that the beneficial influence of the wingtip propellers on the propulsion system and aircraft stagnates with higher values of $S_{P}$. Further insights about the effect of the wingtip propellers on the integrated partial turboelectric propulsion system are provided by taking into account its component masses and its total shaft power.

Figure 15 visualizes the masses of the partial turboelectric propulsion system components $m_{\mathrm{i}}$ in relation to the

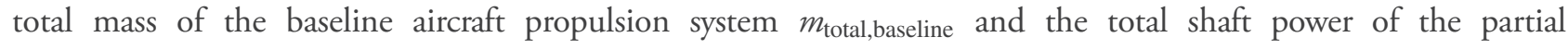


Table 5. DC-DC converter key design parameters.

\begin{tabular}{|l|c|}
\hline Parameter & Value \\
\hline Semicond. device max. current & $450 \mathrm{~A}$ \\
\hline Semicond. device max. voltage & $1,200 \mathrm{~V}$ \\
\hline MOSFET total switching energy (junction temperature $=125^{\circ} \mathrm{C}$ ) & $23 \mathrm{~mJ}$ \\
\hline MOSFET drain-source resistance & $4 \mathrm{~m} \Omega$ \\
\hline Diode reverse recovery energy (junction temperature $=125^{\circ} \mathrm{C}$ ) & $1.1 \mathrm{~mJ}$ \\
\hline Diode resistance & $3.125 \mathrm{~m} \Omega$ \\
\hline Diode forward voltage & $2 \mathrm{~V}$ \\
\hline Switching frequency & $100 \mathrm{kHz}$ \\
\hline Rel. inductor current ripple & 0.3 \\
\hline Rel. max. voltage overshoot & 1.2 \\
\hline Rel. max. voltage ripple (in/out) & 0.5 \\
\hline Equivalent DC resistance applied for inductors and capacitors & $2 \mathrm{~m} \Omega$ \\
\hline Single MOSFET mass & $0.070 \mathrm{~kg}$ \\
\hline Single diode mass & $0.018 \mathrm{~kg}$ \\
\hline
\end{tabular}

turboelectric propulsion system $P_{\text {total }}$ relative to its counterpart of the baseline aircraft $P_{\text {total,baseline }}$ at TOC. $m_{\text {total }}$ comprises the mass of the turboprop engines $m_{\text {engines }}$, the mass of the electrical system $m_{\text {elec. powertrains }}$, the mass of the TMS $m_{\mathrm{TMS}}$, and the masses of additional propulsion system components such as propellers and gearboxes. The latter ones are not separately included in the figure to improve clarity. At $S_{P}=10 \%$, the induced thrust

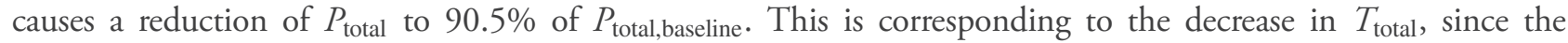
resulting efficiencies are almost the same for all propellers as they share an equal design propeller efficiency at TOC. Also, the corresponding operational points in the scaled propeller performance maps are similar. Associated with the needed shaft power of the wingtip propellers, $m_{\text {elec }}$ powertrains adds a mass penalty of $5.1 \%$

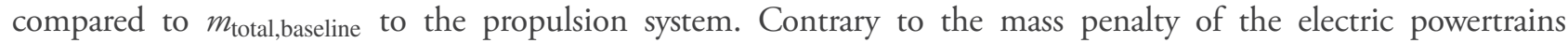
themselves, the necessary cooling of their components results in an insignificant additional mass penalty as $m_{\mathrm{TMS}}$

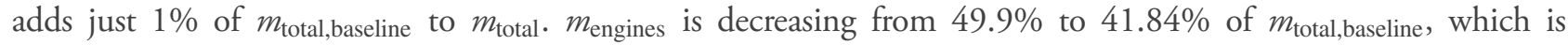

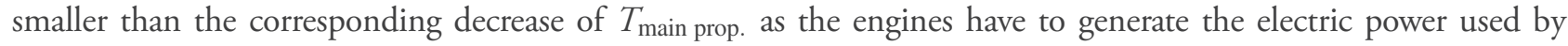
the wingtip propellers. Regarding the entire propulsion system, $m_{\text {total }}$ is reduced to $86.6 \%$ of the baseline propulsion system mass. This decrease is larger than the decrease in $P_{\text {total }}$, which is partially originating from the reduced propeller and gearbox masses since they are highly sensitive to diameters and shaft powers of the propel-

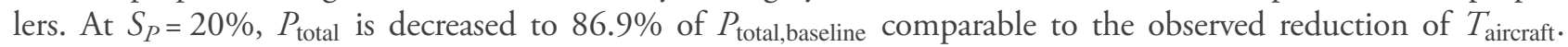

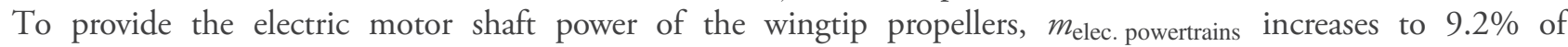

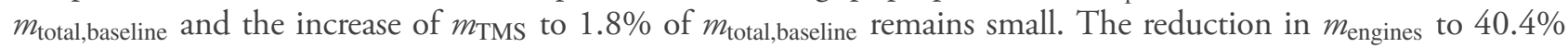
of $m_{\text {total,baseline }}$ is minor, as the engines generate an increasing amount of electric motor power. The single pro-

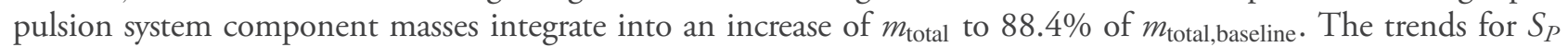
$=30 \%$ are similar to these described for the previous $S_{\mathrm{P}}$ value. Here, $P_{\text {total }}$ decreases to $84.5 \%$ of $P_{\text {total,baseline }}$.

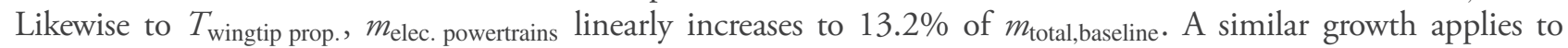
$m_{\text {TMS }}$, which contributes with $2.7 \%$ of $m_{\text {total,baseline }}$ to $m_{\text {total }}$. For the same reasons as described above, $m_{\mathrm{engine}}$ only reduces to $39.6 \%$. Concerning the sum of all propulsion system masses, $m_{\text {total }}$ increases to $91.4 \%$ in comparison with the conventional propulsion system value. Referring to the described trend of the generated induced 


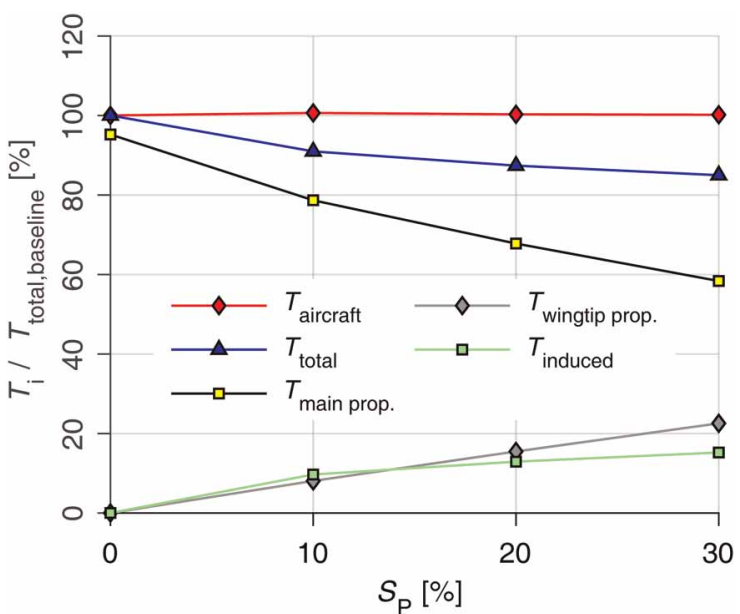

Figure 14. Thrusts of the propulsion system components normalized to the baseline aircraft at top of climb for different $S_{P}$ values.

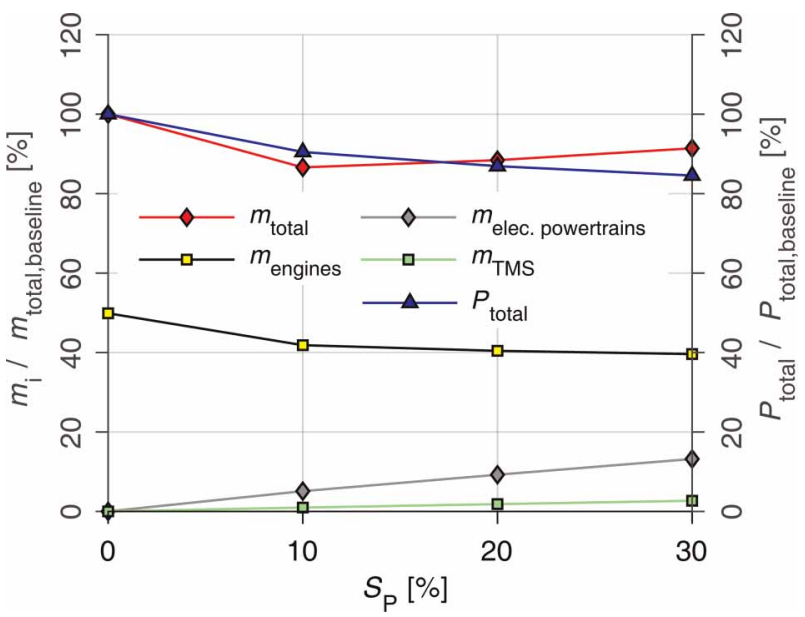

Figure 15. $P_{\text {total }}$ at top of climb and masses of the propulsion system normalized to the baseline aircraft for different $S_{P}$ values.

thrust, its degressive increase for higher values of $S_{P}$ also negatively affects the component masses at $S_{P}=30 \%$. In general, the almost linear increase in $m_{\text {total }}$ combined with an approximately linear increase in $T_{\text {wingtip prop. and }}$ stagnating $T_{\text {induced }}$ is expected to ultimately lead to high propulsion system masses, which outweigh the induced thrust generation.

Table 6 describes the aircraft-integrated partial turboelectric propulsion system design and concludes the propulsion-system-focused investigation in this section. When comparing the partial turboelectric system designs shown in Table 3 with the actual designs resulting from the aircraft integration shown in Table 6, it is noticeable that the values of $P_{\text {total }}$ for the latter one are progressively lower for higher values of $S_{P}$. This power reduction is the consequence of the aerodynamic benefit created by the wingtip propellers, which has a considerably larger impact than the electric powertrain transmission losses described earlier. With respect to $\mathrm{PSFC}_{\text {total }}$, higher values of $S_{P}$ lead to increased $P S F C_{\text {total }}$ values. In comparison with Table 3 , the $\mathrm{PSFC}_{\text {total }}$ values at the same $S_{P}$ value are slightly higher since the turboprop engine becomes less efficient due to its decreased size.

Figure 16 provides more insight into the overall aircraft design parameters. The changes in the operating empty mass (OEM), the maximum takeoff mass (MTOM), and the block fuel mass ( $m_{\text {block fuel }}$ ) of to the partial turboelectric aircraft relative to the baseline aircraft are shown. The partial turboelectric aircraft's OEM decreases by $2.7 \%$ at $S_{P}=10 \%$. This mass reduction is the result of reduced structure mass in consequence of the MTOM reduction of $1.7 \%$ and savings in nacelle masses as $P_{\text {total }}$ is lowered for the associated sizing conditions. Furthermore, the reduction in $m_{\text {total }}$ also contributes to the reduction in OEM. The corresponding $m_{\text {block fuel }}$ at $S_{P}=10 \%$ decreases by $4.4 \%$. Looking at the share of OEM and $m_{\text {block fuel }}$ in the MTOM reduction $(\triangle \mathrm{MTOM})$, $m_{\text {block fuel }}$ has a $19.3 \%$ share and OEM has a $90.4 \%$ share.

At $S_{P}=20 \%$, OEM is not decreasing any more. This is the result of two opposing effects. On the one hand, the comparatively small additional reduction in MTOM by just $0.4 \%$, which in combination with the decrease in $P_{\text {total }}$ and the accompanying lower nacelle masses, only leads to a small structural mass saving. On the other hand, the increase in $m_{\text {total }}$ primarily due to the mass penalty of the electric powertrains is overcompensating the mass reduction induced by the smaller MTOM. The reduction in $m_{\text {block fuel }}$ however, is approximately doubled to $8.4 \%$ of the baseline aircraft's $m_{\text {block fuel }}$. Also, putting the mass reductions for $S_{P}=20 \%$ in relation to $\triangle \mathrm{MTOM}$, shows that the OEM increase is $3.8 \%$ of $\triangle \mathrm{MTOM}$ and the reduction in $m_{\text {block fuel }}$ is $80.5 \%$ of $\triangle \mathrm{MTOM}$.

Finally, at $S_{P}=30 \%$, OEM is $2.3 \%$ lower than the baseline aircraft's OEM. This increase in OEM, compared to $S_{P}=20 \%$, originates from an increasing $m_{\text {total }}$ mainly caused by the increase of $m_{\text {elec. powertrains. }}$ The structural mass is only marginally lower due to a minimum change in MTOM and a minor decrease of the nacelle masses as the additional reduction in $P_{\text {total }}$ is also small. The stagnating MTOM and the increasing growth rate of OEM are associated with an additional decrease in $m_{\text {block fuel }}$ of $2.1 \%$ or a total reduction of $10.5 \%$ compared to $m_{\text {block fuel }}$ of the baseline aircraft.

From the observations described in the previous paragraphs, several conclusions can be drawn. Most importantly, the advantage of the partial turboelectric propulsion system observed in the aircraft-integration relies on the aerodynamic benefit created due to the utilization of the wingtip propellers. These propulsors provide a 
Table 6. Shaft powers and $\mathrm{PSFC}_{\text {total }}$ of the aircraft-integrated partial turboelectric propulsion system at top of climb.

\begin{tabular}{|l|l|l|l|l|}
\hline $\mathrm{S}_{\mathrm{P}}$ & $P_{\text {main prop. }}$ & $P_{\text {wingtip prop. }}$ & $P_{\text {total }}$ & $\mathrm{PSFC}_{\text {total }}$ \\
\hline$\%$ & $\mathrm{~kW}$ & $\mathrm{~kW}$ & $\mathrm{~kW}$ & $\mathrm{~kg} / \mathrm{kWh}$ \\
\hline 0 & 4,150 & 0 & 4,150 & 0.1859 \\
\hline 10 & 3,379 & 375 & 3,755 & 0.1885 \\
\hline 20 & 2,885 & 721 & 3,607 & 0.1908 \\
\hline 30 & 2,456 & 1053 & 3,509 & 0.1930 \\
\hline
\end{tabular}

growing amount of induced thrust for increased $S_{P}$ values, which is found to be significant compared to the ratio of the wing's induced drag to the overall drag of the wing. At $S_{P}=30 \%$, the predicted induced thrust is almost half of this drag ratio, which seems rather optimistic as the induced drag can be only partly influenced by such wingtip propellers. Furthermore, the aircraft assessed feature a high wing aspect ratio of 12 and according to the literature available on this topic (see Miranda and Brennan (1986) for instance), the influence of devices to reduce the induced drag of the wing is decreasing for increasing wing aspect ratios. Estimating that the induced thrust generated by the wingtip propellers is substantially decreased compared to the predictions presented, the assessment of the partial turboelectric propulsion system on aircraft level would heavily change and could lead to a block fuel increase. For future investigations, the use of high fidelity methods or wind-tunnel test data, instead of the analytical approach, is strongly recommended. Regardless of the induced thrust prediction method, for increasing $S_{P}$ values, the mass increase caused by the electric powertrain is expected to outweigh the effect of the induced thrust generation at a certain point. Although such a global minimum in $m_{\text {block fuel }}$ due to these opposing effects was expected for the selected range of $S_{P}$ values, a different induced thrust prediction method could accomplish that and therefore identify an optimal $S_{P}$ value for the type of aircraft and mission investigated.

\section{Conclusions and outlook}

This paper presents a novel preliminary design and evaluation tool for partial turboelectric propulsion systems and a case study for a commercial single-aisle turboprop aircraft. The included parametric studies of the electric powertrain illustrate that the design efficiency of the optimized electric powertrain is approximately constant and depends primarily on the efficiencies of the electric machines. The electric powertrain mass shows a more or less linear increase with its design power. Nevertheless, several effects, e.g., related to cable insulation, lead to a

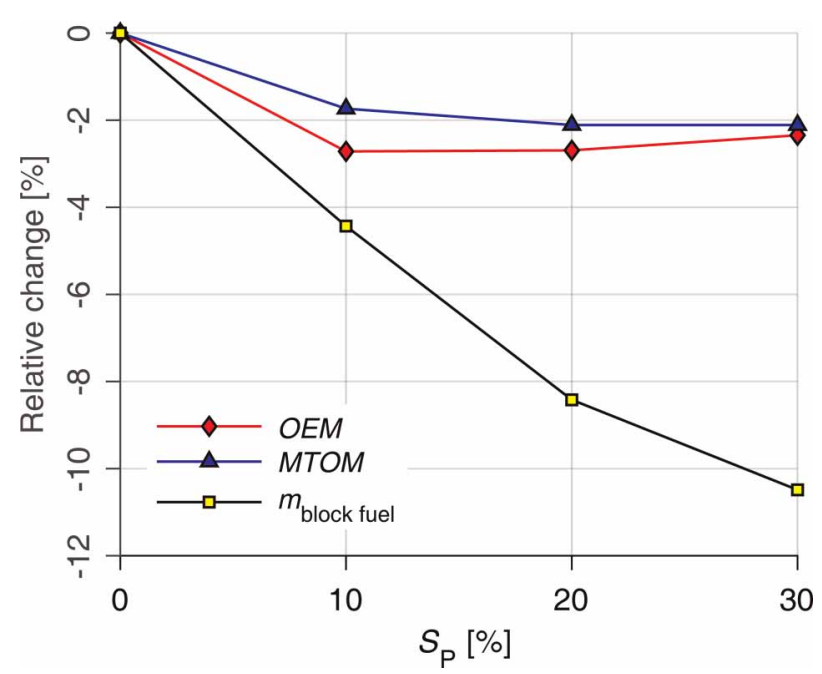

Figure 16. Masses of the partial turboelectric aircraft normalized to the baseline aircraft for different $S_{P}$ values. 
certain deviation. This, in turn, results in rising power-to-weight ratios at increasing electric system powers. By only taking the isolated propulsion system into account, the electrification does not lead to any benefits in respect of $\mathrm{PSFC}_{\text {total }}$. Instead, electrification causes additional complexity, mass and losses. By way of rough estimation, each $10 \%$ increase in $S_{P}$ results in a $1 \%$ higher $\mathrm{PSFC}_{\text {total }}$.

However, the results change when the partial turboelectric propulsion system is assessed at aircraft level. As part of the associated aircraft comparison, electrifying a turboprop aircraft by using turboelectrically driven wingtip propellers was found to be beneficial with regard to the block fuel consumption. The wingtip propellers add induced thrust to the overall system and thus reduce the power demand on the partial turboelectric propulsion system. The lowest block fuel consumption was found at the maximum $S_{P}$ value investigated, 30\%. At this value, the partial turboelectric aircraft achieves a block fuel reduction in the order of magnitude of $10 \%$. However, the advantage of the partial turboelectric propulsion system observed in the aircraft-integration heavily depends on the aerodynamic benefit of the wingtip propellers and therefore on the used prediction method. To demonstrate the coupling of the novel preliminary design tool and the existing aircraft design environment the results are sufficient. In order to accurately model the aerodynamic effect of wingtip propellers, further work with a more sophisticated method would be needed. One the one hand, as the analytical approach seem to be rather optimistic, a more accurate induced drag prediction could nullify the potential for block fuel reduction. On the other hand, high fidelity methods could lead to the identification of an optimum $S_{P}$ value with a global fuel burn minimum. This optimum had been expected in the range of the $S_{P}$ values examined, but could not be identified. Regarding other fields of future work, the effects of the wingtip propellers on the vertical tail size could be modeled more precisely. Including electric cross feed, for example, could result in a smaller empennage with less drag. To further isolate the effects of electrification, the turboelectrically driven wingtip propellers could be compared with small turboprop engines. This concept however, could include in safety concerns or operational restrictions. For instance, the wingtip propeller would have to run at idle during taxiing and could not be started just before takeoff like an electrically driven one. Apart from wingtip propellers, winglets or even foldable wingtips could also be used to decrease the induced drag without significantly increasing the aircraft's wing span during ground operations.

Furthermore, several additional aspects of the partial turboelectric propulsion system modeling can be studied. Regarding the operation of the wingtip propellers, alternative operational strategies should be studied and compared. Maximizing the power of the wingtip propellers and the induced thrust generation throughout the whole flight envelope, by implementing more complex operating strategies, could also lead to a further reduction in block fuel consumption. Additionally, more sophisticated insulation modeling, especially for power electronics, could be included. This would probably also affect the optimum number of turns in the electric machines. These and other aspects will form part of further development of the tool and will be the subject of future publications.

In summary, the goal to develop a novel preliminary design tool and evaluation for partial turboelectric aircraft propulsion systems has been achieved. The case study has shown that a holistic evaluation of the aircraft, its propulsion system and the entire mission is necessary to evaluate the impact of electrification.

\section{Nomenclature}

\section{Symbols}

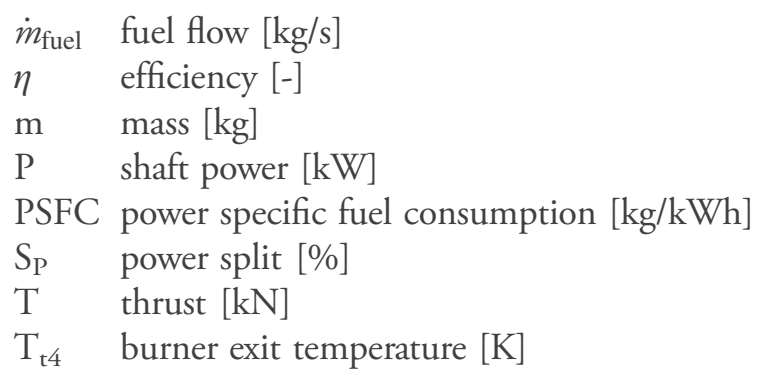

\section{Abbreviations}

AC alternating current

DC direct current

HPC high-pressure compressor 
HPT high-pressure turbine

IPC intermediate-pressure compressor

IPT intermediate-pressure turbine

ISA international standard atmosphere

LPT low-pressure turbine

MOSFET metal-oxide-semiconductor field-effect transistor

MTOM maximum takeoff mass

OEM operating empty mass

PMSM permanent magnet synchronous machine

$\mathrm{SiC} \quad$ silicon carbide

TLARs top-level aircraft requirements

TMS thermal management system

TOC top of climb

\section{Acknowledgments}

We would like to thank everyone involved in the IVeA project for their dedication to its success. Additionally, we thank Jonas Cäsar and Christian Klumpp for their support for this publication.

\section{Funding sources}

This research received funding as part of the IVeA project, a research project supported by the Federal Ministry for Economic Affairs and Energy in the German Aviation Research Program.

\section{Competing interests}

Markus Pohl declares that he has no conflict of interest. Jo Köhler declares that he has no conflict of interest. Hagen Kellermann declares that he has no conflict of interest. Michael Lüdemann declares that he has no conflict of interest. Daniel Weintraub declares that he has no conflict of interest. Peter Jeschke declares that he has no conflict of interest. Mirko Hornung declares that he has no conflict of interest.

\section{References}

Advisory Council for Aeronautics Research in Europe. (2011). Flightpath 2050 - Europe's Vision for Aviation. Available at: https://www. acare4europe.org/documents/latest-acare-documents/acare-flightpath-2050 [Accessed 11 Sep. 2019].

Antcliff K. R. and Capristan F. M. (2017). Conceptual design of the parallel electric-gas architecture with synergistic utilization scheme (PEGASUS) concept. In 18th AIAA/ISSMO Multidisciplinary Analysis and Optimization Conference 2017. Curran Associates Inc. Available at: http://dx.doi.org/10.2514/6.2017-4001 [Accessed 23 Sep. 2020].

Anton F. (2019). e-Aircraft: Hybrid-elektrische Antriebe für Luftfahrzeuge. In 14. Tag der Deutschen Luft- und Raumfahrtregionen, Potsdam. Available at: https://www.bbaa.de/fileadmin/user_upload/02-preis/02-02-preistraeger/newsletter-2019/02-2019-09/02_ Siemens_Anton.pdf [Accessed 20 Jan. 2021].

Arbeitskreis Masseanalyse des Luftfahrttechnischen Handbuchs. (2008.) Luftfahrttechnisches Handbuch. Ottobrunn: LTH-Koordinierungsstelle.

Athanasakos G., Aretakis N., Alexiou A., and Mathioudakis K. (2020). Turboelectric distributed propulsion Modelling mccounting for fan boundary layer ingestion and inlet distortion. In ASME Turbo Expo 2020: Turbomachinery Technical Conference and Exposition. American Society of Mechanical Engineers Digital Collection.

Binder A. and Schneider T. (2007). High-speed inverter-fed AC drives. In International Aegean Conference on Electrical Machines and Power Electronics, 2007. IEEE Service Center, pp. 9-16.

Blaesser N. J. and Frederick Z. J. (2020). Tail sizing considerations for wingtip propulsor driven aircraft applied to the Parallel Electric-Gas Architecture with Synergistic Utilization Scheme (PEGASUS) concept. In AIAA Aviation Forum.

Brown G. V., Kascak A. F., Ebihara B., Johnson D., Choi B., et al. (2005). NASA Glenn Research Center Program in High Power Density Motors for Aeropropulsion.

Cheng F. C. (1994). Insulation thickness determination of polymeric power cables. IEEE Transactions on Dielectrics and Electrical Insulation. 1 (4): 624-629. http://dx.doi.org/10.1109/94.311705

Committee on Propulsion and Energy Systems to Reduce Commercial Aviation Carbon Emissions. (2016.) Commercial Aircraft Propulsion and Energy Systems Research: Reducing Global Carbon Emissions. Washington, DC: National Academies Press.

Cree Inc. (2020). CAB425M12XM3 Data Sheet: Wolfspeed 1200 V, 425 A All-Silicon Carbide Switching-Optimized, Half-Bridge Module. Available at: http://www.wolfspeed.com/media/downloads/1594/cab425m12xm3.pdf [Accessed 18 Aug. 2020].

Daly M. (2014.) IHS Jane's Aero-Engines. Coulsdon, Surrey: IHS Global.

EA Internacional. (2020). Propulsion Object Oriented Simulation Software (PROOSIS). Available at: https://www.ecosimpro.com/ products/proosis/ [Accessed 29 Sep. 2020]. 
Eviation. (2020). Alice Commuter. Available at: https://www.eviation.co/alice/ [Accessed 1 Sep. 2020].

GasTurb GmbH. (2020). GasTurb 13: Design and Off-Design Performance of Gas Turbines. Available at: http://download.gasturb.de/ Manuals/GasTurb13.pdf [Accessed 18 Aug. 2020].

Gologan C. (2010). Method for the Comparison of Transport Aircraft with Blown Flaps. PhD thesis, Technical University of Munich. Grieb H. (2004). Projektierung von Turboflugtriebwerken. Basel: Technik der Turboflugtriebwerke, Springer Basel AG.

Integral Powertrain Ltd. (2020). Integral e-Drive - SPM 236e Aero. Available at: https://integralp.com/?tab=our-electric-drives [Accessed 21 July 2020].

Kang S., Roumeliotis I., Zhang J., Pachidis V., and Broca O. (2021). Assessment of engine operability and overall performance for parallel hybrid electric propulsion systems for a single-aisle aircraft. In ASME Turbo Expo 2021: Turbomachinery Technical Conference and Exposition. American Society of Mechanical Engineers Digital Collection.

Kellermann H., Lüdemann M., Pohl M., and Hornung M. (2021). Design and optimization of ram air-based thermal management systems for hybrid-electric aircraft. Aerospace. 8 (1): 3.

Köhler J. and Jeschke P. (2021). Conceptual design and comparison of hybrid electric propulsion systems for small aircraft. Council of European Aerospace Societies Aeronautical Journal. 12 (4): 907-922. http://dx.doi.org/10.1007/s13272-021-00536-4

Kurzke J. (2007). About simplifications in gas turbine performance calculations. In ASME Turbo Expo 2007: Power for Land, Sea, and Air. American Society of Mechanical Engineers Digital Collection, pp. 493-501.

Loth J. L. and Loth F. (1984). Induced drag reduction with wing tip mounted propellers. In 2nd Applied Aerodynamics Conference. American Institute of Aeronautics and Astronautics.

Miranda L. R. and Brennan J. E. (1986). Aerodynamic effects of wingtip-mounted propellers and turbines. In 4th Applied Aerodynamics Conference. American Institute of Aeronautics and Astronautics, pp. 221-228.

Müller G., Vogt K., and Ponick B. (2008.) Berechnung elektrischer Maschinen, Vol. 2 of Elektrische Maschinen. 6th rev. edn. Weinheim: Wiley-VCH.

NLR - Royal Netherlands Aerospace Centre. (2020). Gas turbine Simulation Program (GSP). Available at: https://www.gspteam.com/ [Accessed 29 Sep. 2020].

PACE Aerospace Engineering \& Information Technology GmbH. (2012). Pacelab Aircraft Preliminary Design (version 3.0.1).

Perullo C. A., Trawick D., Clifton W., Tai J. C. M., and Mavris D. N. (2014). Development of a suite of hybrid electric propulsion modeling elements using NPSS. In ASME Turbo Expo 2014: Turbomachinery Technical Conference and Exposition. American Society of Mechanical Engineers Digital Collection.

Pipistrel Group. (2020). Velis Electro. Available at: http://www.pipistrel-aircraft.com/aircraft/electric-flight/velis-electro-easa-tc/ [Accessed 1 Sep. 2020].

Pornet C. (2018). Conceptual Design Methods for Sizing and Performance of Hybrid-Electric Transport Aircraft. PhD thesis, Technical University of Munich.

Raymer D. (2006). Aircraft Design: A Conceptual Approach, AIAA education series, 4th edn. Reston, VA: American Institute of Aeronautics and Astronautics.

Schröder D. and Marquardt R. eds (2019). Leistungselektronische Schaltungen: Funktion, Auslegung und Anwendung, 4th edn. Springer Berlin Heidelberg, Berlin, Heidelberg. Available at: http://dx.doi.org/10.1007/978-3-662-55325-1 [Accessed 21 Jul. 2020].

Seitz A. (2012). Advanced Methods for Propulsion System Integration in Aircraft Conceptual Design. PhD thesis, Technical University of Munich.

SEMIKRON International GmbH. (2020). SemiSel V5. Available at: https://semisel.semikron.com/\&hash;/home [Accessed 18 Aug. 2020].

Sielemann M., Coïc C., Zhao X., Diamantidou D. E., and Kyprianidis K. (2020). Multi-point design of parallel hybrid aero engines. In 2020 AIAA/IEEE Electric Aircraft Technologies Symposium (EATS), pp. 1-18.

Siemens A. G. (2018). Electric Flight: Highest power density inverter for electric aircraft. Available at: https://press.siemens.com/global/en/ feature/electric-flight [Accessed 21 Jul. 2020].

Southwest Research Institute. (2020). Numerical Propulsion System Simulation (NPSS). Available at: https://www.swri.org/consortia/ numerical-propulsion-system-simulation-npss [Accessed 29 Sep. 2020].

Strack M., Pinho Chiozzotto G., Iwanizki M., Plohr M., and Kuhn M. (2017). Conceptual design assessment of advanced hybrid electric turboprop aircraft configurations. In 17th AIAA Aviation Technology, Integration, and Operations Conference. AIAA AVIATION Forum, American Institute of Aeronautics and Astronautics, pp. 49-68.

Torenbeek E. (2010.) Synthesis of Subsonic Airplane Design. Dordrecht: Springer Netherlands.

Vollmer U. (2012). Entwurf, Auslegung und Realisierung eines verlustoptimierten elektrischen Antriebs für Hybridfahrzeuge. PhD thesis, Technische Universität Berlin.

Vratny P. C. (2019). Conceptual Design Methods of Electric Power Architectures for Hybrid Energy Aircraft. PhD thesis, Technical University of Munich.

Vratny P. C. and Hornung M. (2018). Sizing considerations of an electric ducted fan for hybrid energy aircraft. Transportation Research Procedia. 29: 410-426. http://dx.doi.org/10.1016/j.trpro.2018.02.037

Wainauski H. S., Rohrbach C., and Wynosky T. A. (1987). Prop-fan performance Terminology. In SAE Technical Papers. SAE International.

Walsh P. P. and Fletcher P. (2008.) Gas Turbine Performance. 2nd edn. Oxford: Blackwell Science.

Wintrich A., Nicolai U., Tursky W., and Reimann T. eds (2015.) Application Manual Power Semiconductors. 2nd rev. edn. Ilmenau: ISLE Verlag.

Wortmann G. (2018). Electric Machinery Preliminary Design Report. Available at: https://www.centreline.eu/wp-content/uploads/ CENTRELINE_SIEMENS_D4.04_R1.0.pdf [Accessed 18 Aug. 2020].

Zunum Aero. (2020). Zunum Aircraft. Available at: https://zunum.aero/aircraft/ [Accessed 1 Sep. 2020]. 